\title{
International Trade Risk and the Role of Banks
}

Niepmann, Friederike and Tim Schmidt-Eisenlohr

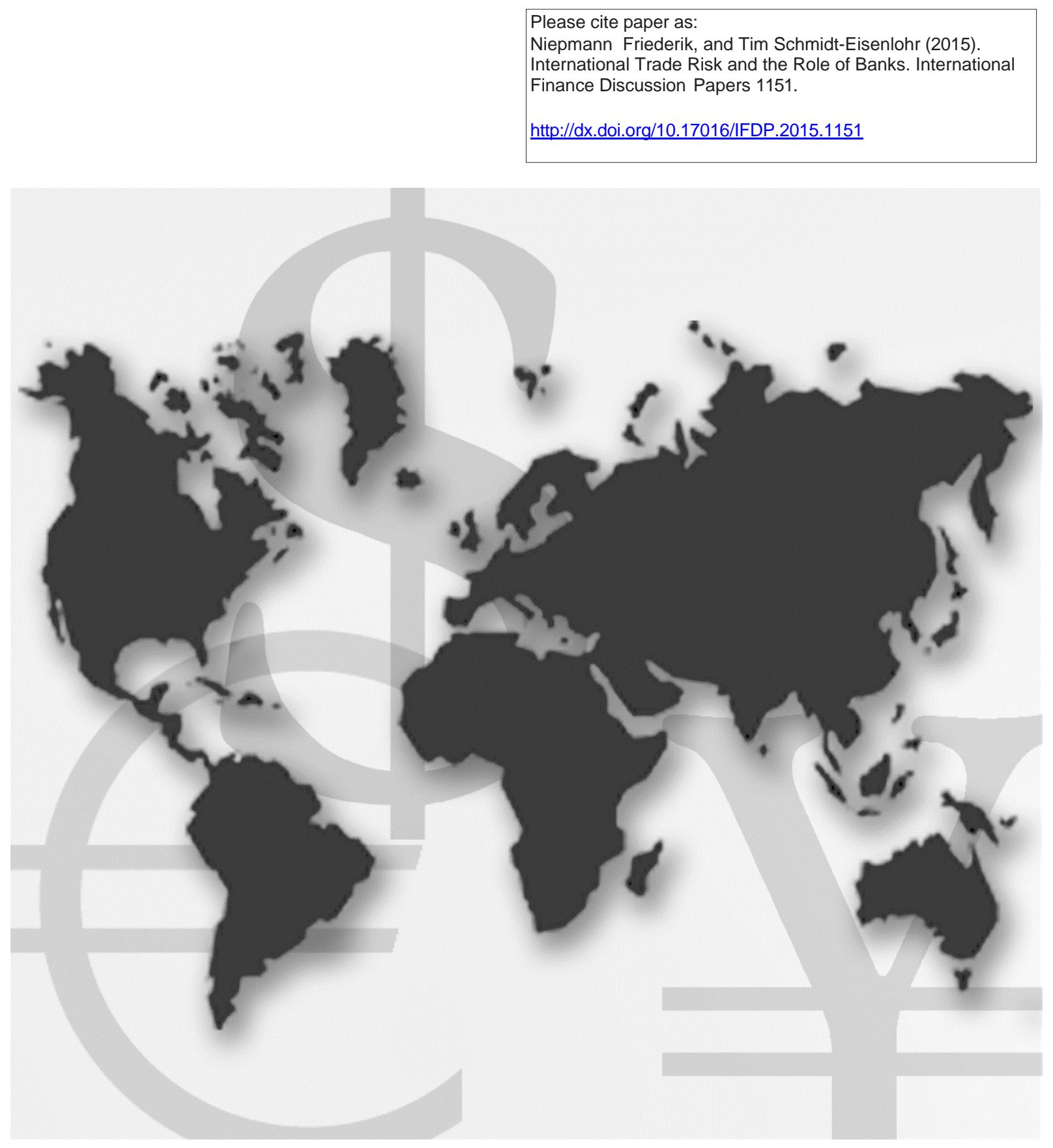

\section{International Finance Discussion Papers}

Board of Governors of the Federal Reserve System

Number 1151

August 2015 
Board of Governors of the Federal Reserve System

International Finance Discussion Papers

Number 1151

August 2015

\section{International Trade Risk and the Role of Banks}

Friederike Niepmann

Tim Schmidt-Eisenlohr

NOTE: International Finance Discussion Papers are preliminary materials circulated to stimulate discussion and critical comment. References to International Finance Discussion Papers (other than an acknowledgment that the writer has had access to unpublished material) should be cleared with the author or authors. Recent IFDPs are available on the Web at www.federalreserve.gov/pubs/ifdp/. This paper can be downloaded without charge from the Social Science Research Network electronic library at www.ssrn.com. 


\title{
International Trade, Risk and the Role of Banks
}

\author{
Friederike Niepmann and Tim Schmidt-Eisenlohr*
}

\begin{abstract}
International trade exposes exporters and importers to substantial risks. To mitigate these risks, firms can buy special trade finance products from banks. This paper explores under which conditions and to what extent firms use these products. We find that letters of credit and documentary collections cover about 10 percent of U.S. exports and are preferred for larger transactions, indicating substantial fixed costs. Letters of credit are employed the most for exports to countries with intermediate contract enforcement. Compared to documentary collections, they are used for riskier destinations. We provide a model that rationalizes these empirical findings and discuss implications.
\end{abstract}

Keywords: trade finance, multinational banks, risk, letter of credit JEL-Codes: F21, F23, F34, G21

${ }^{*}$ The authors are staff economists in the Division of International Finance, Board of Governors of the Federal Reserve System, Washington, D.C. 20551 U.S.A. The views in this paper are solely the responsibility of the author(s) and should not be interpreted as reflecting the views of the Board of Governors of the Federal Reserve System or of any other person associated with the Federal Reserve System. The authors are grateful to JaeBin Ahn, Andrew Bernard, Giancarlo Corsetti, Galina Hale, Charles Kahn, Rod Ludema, Morten Olsen, Philipp Schnabl, Valerie Smeets and Catherine Thomas for helpful comments, and also thank workshop participants at the New York FED, NYU and UAB, the 2014 EITI Conference, the Ifo Institute conference on State Export Credit Guarantees in a Globalized World and the 2014 conference of the CEPR working group on the Macroeconomics of Global Interdependence. The authors also thank Geoffrey Barnes for excellent research assistance, and the SWIFT Institute for providing some of the data used in this research. This version is from February 2015. The paper is currently under revision for a refereed journal. 


\section{Introduction}

When firms trade, they have to decide how to settle the transaction and, thereby, how to manage the associated risk. To mitigate risk, exporters and importers employ letters of credit and documentary collections offered by banks. ${ }^{1}$ Using new data from SWIFT complemented by information from the Federal Reserve Board, this paper shows when firms use these instruments and it proposes a model of payment contract choice to rationalize the patterns in the data.

Firms' payment choices are central for international economic activity. When exporters rely on letters of credit and documentary collections, the availability of these bank products and their costs directly impact the profitability of trade transactions and, therefore, firms' export behavior. At the same time, because banks in the source and the destination country collaborate to provide these services, their availability and costs depend on financial conditions at home and abroad. Letters of credit and documentary collections therefore represent a channel through which financial shocks can be transmitted across borders.

The role of banks and their trade finance services were highlighted by the financial crisis in 2008/2009, which triggered policy responses. ${ }^{2}$ For example, while many development banks had trade finance programs before the crisis, the support was ramped up substantially after 2008, especially the public confirmation of letters of credit. ${ }^{3}$ Moreover, the risk weights on letters of credit originally proposed by the Basel Committee on Banking Supervision in 2010 were brought down over concerns that the new rules on capital and leverage would make trade finance too costly and harm trade. ${ }^{4}$

\footnotetext{
${ }^{1}$ In a letter of credit, the importer's bank guarantees payment to an exporter upon proof that the goods were delivered to the importer. A documentary collection consists of ownership documents that are forwarded by the exporter's bank to the importer's bank; the importer receives the documentary collection only upon payment. The two payment methods are illustrated in figures 1 and 2. For a more detailed discussion, see section 2 .

${ }^{2}$ Based on data from Japan and Peru, respectively, Amiti and Weinstein (2011) and Paravisini et al. (forthcoming) find that banks shocks affect international trade. Niepmann and Schmidt-Eisenlohr (2013b) show that reductions in the supply of letters of credit by banks reduce U.S. exports using the FFIEC 009 data also employed in this paper.

${ }^{3}$ In the midst of the crisis, the G20 committed to extending the public support for trade finance by $\$ 250$ billion, worried that firms would stop exporting without bank guarantees. The International Finance Organization, which is a part of the World Bank Group, now conducts a $\$ 5$ billion program that mostly confirms letters of credit; see IFC (2012).

${ }^{4}$ Specifically, trade finance is an off-balance sheet item that will receive a higher risk weight under the 2010 international agreement known as Basel III, produced by the Basel Committee on Banking Supervision; and trade finance will also weigh on the Basel III leverage ratio.
} 
Despite the relevance of understanding firms' payment contract choices for trade costs, the transmission of shocks and the public provision of trade finance, our knowledge of the topic is still very limited. In particular, how important trade finance instruments are for international trade and under which circumstances they are used remain open questions that have been difficult to answer due to a lack of data. This paper contributes to filling this gap. Our work explores the use of letters of credit and documentary collections by U.S. exporters, employing data from SWIFT as well as U.S. regulatory filings, and it presents a model that extends and significantly modifies the theory in Schmidt-Eisenlohr (2013) to explain the empirical facts.

The data set from SWIFT contains the number of LCs and DCs handled by U.S. banks by location of the issuing/sending bank as well as information on the corresponding transaction values. These data demonstrate that trade finance products are very relevant for exporting although less prevalent than what previous studies have found. By value of exports, letters of credit were used in 2012 for 8.8 percent of all U.S. export transactions, while documentary collections were employed for 1.2 precent. These numbers are far below the 30-40 percent of bank intermediated trade found in IMF surveys. ${ }^{5}$ They also differ substantially from the numbers reported in Antràs and Foley (forthcoming) who study the payment choices of one large U.S. food exporter and report that letters of credit are used for 5.5 percent of its exports while documentary collections make up 10.7 percent of transaction values. This highlights that asking banks how they perceive the share of bank intermediated trade compared to other payment forms can lead to large biases and raises the question how one should interpret the available survey data. Similarly, as Antràs and Foley (forthcoming) acknowledge, there are limitations to the generalizability of results based on data from a single firm.

The use of letters of credit and documentary collections varies considerably by export market. Across destinations, the share of sales that are settled with LCs takes values between zero and 90 percent in the SWIFT data; for DCs, usage lies between zero and 10 percent. As we show, this variation is systematically related to factors associated with firms' optimal choices for payment arrangements. In particular, the use of LCs and DCs depends on the extent to which contracts can be enforced in the destination country. We find that LCs are

\footnotetext{
${ }^{5}$ See IMF (2009). Results of the first four IMF surveys have been summarized by Asmundson et al. (2011).
} 
used the most for exports to countries with an intermediate level of quality in their legal institutions, while the use of DCs largely increases with the destination's rule of law. LCs are employed relatively more than DCs for export markets where contract enforcement is weaker.

Although the main objective of an LC is to reduce financial risk, it comes with a price and so tends not to be used in either the least risky or most risky situations. This finding can be explained by the optimal contract choice of firms. The basic intuition is that the value of risk mitigation through bank intermediation is offset to a degree by the cost of the intermediation. Because banks can reduce but cannot eliminate the risk of a trade transaction, the fees they charge rise with the remaining risk they take on. For the riskiest destination countries, bank fees are so high that exporters prefer cash-in-advance. In that case, the importer pays before the exporter produces, and payment risk is eliminated. Similarly, LCs are not used for lowrisk destinations; for those transactions, the exporter can save on bank fees by bearing the risk itself. ${ }^{6}$

The theoretical model presented in section 3 explains these mechanisms in detail. We modify and extend the theoretical framework in Schmidt-Eisenlohr (2013) in three ways. First, we introduce documentary collections as a fourth payment type, which have not been modeled before. Second, we present a new formulation of the LC contract. The LC fee is no longer constant as in Schmidt-Eisenlohr (2013); instead it is a function of the importer's default risk and consists of both a fixed and a variable component. These assumptions reflect key features of LCs that were not accounted for previously and are essential for matching the empirical patterns. Third, we simulate the model for a continuum of exporters and importers that face random shocks to the profitability of each payment form.

Another key factor that determines the use of LCs and DCs in U.S. exports is a destination's distance from the U.S. We find that distance has a positive effect on the number of LCs and DCs sent. This suggests that long distance trade is inherently more risky, which makes firms rely more on bank guarantees. In line with this view, we find that a destination's quality of institutions affects the use of LCs only when we consider countries whose distance from the United States is above the median. The use of DCs, in contrast, always increases

\footnotetext{
${ }^{6}$ For cash-in-advance transactions, the importer pays before the exporter delivers. For open-account transactions, the exporter delivers before the importer pays.
} 
with a destination's quality of legal institutions, regardless of its distance from the United States.

We also show that the average size of trade transactions differs by type of payment contract. The average for letter-of-credit transactions is by far the largest ( $\$ 716.2$ thousand), followed by that for documentary collections ( $\$ 138.7$ thousand). Transactions that do not rely on bank intermediation (cash-in-advance and open account) are on average much smaller (\$39.2 thousand). These findings are in line with the theory in which LCs and DCs require the payment of fixed fees that cover the bank's costs for document handling and screening. These fixed fees imply that LCs and DCs are more attractive for firms when shipments are large. The results on size of transaction thus provide evidence for the existence of substantial fixed costs in the provision and use of trade finance products.

Literature Previous empirical work on payment contract choice focuses mostly on the trade-off between cash-in-advance and open account. A few studies provide some evidence on the use of LCs, but none have comprehensive data or explicitly analyze the use of DCs. Antràs and Foley (forthcoming) exploit information on the contract choices of one large U.S. food exporter. They show that the firm's use of LCs decreases with the degree of contract enforcement in the destination country and that the firm is more likely to use an LC when interacting with a new customer. Hoefele et al. (2013) employ firm-level data to study how country characteristics affect firms' payment choices. Relying on World Bank surveys, they find a role for product complexity in the choice between pre- and post-delivery payments. Glady and Potin (2011) employ SWIFT data from 2006 without information on the value of LC transactions to analyze payment contracts across countries. They find that the number of LC transactions increases with country risk. Demir and Javorcik (2014) use data from Turkey to analyze the role of industry-level competition for the optimal payment contract choice; the authors observe the share of exports that use LCs, but they pool bankintermediated trade with cash-in-advance transactions. ${ }^{7}$ Ahn (2014) employs detailed data on the payment choice of Colombian firms, focusing on the prevalence of open account.

Two papers about the effects of shocks to the supply of trade finance and general loans on trade also contain information on payment forms used. Del Prete and Federico (2012) study

\footnotetext{
${ }^{7}$ Turkcan and Avsar (2014) employ the same data to test the key predictions of Schmidt-Eisenlohr (2013) regarding the use of cash-in-advance and open account terms.
} 
the effect of financial shocks on trade based on detailed information on loans and guarantees extended by Italian banks. Using matched importer-exporter data from Colombia, Ahn (2013) investigates whether financial shocks in 2008-2009 affected the use of LCs. ${ }^{8}$

Several papers propose theories of payment contract choice based on the model in SchmidtEisenlohr (2013). Antràs and Foley (forthcoming) extend the framework to a dynamic setting. Glady and Potin (2011) introduce heterogeneous firms and asymmetric information into the model. Hoefele et al. (2013) derive new predictions on the role of industry complexity. Ahn (2014) develops an alternative model that explains the popularity of open account transactions by their self-liquidating and recourse nature. ${ }^{9}$ None of the aforementioned papers study DCs or derive predictions that match the empirical patterns documented here.

Our analysis of trade finance and payment contract choice also relates to the large literature on trade credit $^{10}$ and to the literature on financial conditions and comparative advantage. $^{11}$

The remainder of the paper is structured as follows. Section 2 provides background information on the different modes of payment in international trade. Section 3 discusses the theoretical model. Section 4 presents the empirical findings. Section 5 concludes.

\section{Payment Contracts in International Trade}

\subsection{The Different Payment Forms}

When an exporter and an importer trade, they have to decide how to settle the transaction. Under one option, the exporter produces the good and the importer pays upon receipt (open

\footnotetext{
${ }^{8}$ For more papers on the effect of financial shocks on trade, see also Amiti and Weinstein (2011), Paravisini et al. (forthcoming) and Niepmann and Schmidt-Eisenlohr (2013b).

${ }^{9}$ In an earlier version, Ahn (2011), the focus was on the effect of changes in aggregate default risk on the ratio of exports to domestic sales; in that model, LCs become relatively less attractive in a crisis because risks increase both for importers and banks.

${ }^{10}$ Granting trade credit corresponds to settling a transaction with an open account, one of the payment forms we consider. Several papers in this literature analyze the substitutability between inter-firm finance and bank finance, although none of them exploit data on bank guarantees as we do here. Among the theoretical contributions are Ferris (1981), Petersen and Rajan (1997), Biais and Gollier (1997), Wilner (2000), Burkart and Ellingsen (2004) and Cunat (2007). Empirical studies include Ng et al. (1999), Love et al. (2007), Giannetti et al. (2011) and Klapper et al. (2012). See also Eck et al. (2014). Our results may be applicable to this literature because the trade-offs involved in trade credit are very similar to those in international trade finance.

${ }^{11}$ See, in particular, Beck (2003) and Manova (2013) on how financial development affects trade patterns.
} 
account). Under another, the importer pays before the exporter produces the good (cashin-advance). In each case, one of the trading partners bears substantial risk: With an open account, the exporter may never receive payment. Under cash-in-advance, the importer may never obtain the goods. To reduce the risk of the transaction for either party, firms can turn to banks, which can act as intermediaries and thereby attenuate enforcement problems. ${ }^{12}$ The two most common trade finance instruments provided by banks are letters of credit and documentary collections.

Letter of credit The importer initiates the letter of credit transaction (figure 1) by having its bank issue the instrument to the exporter. The letter of credit guarantees that the issuing bank will pay the agreed contract amount when the exporter proves that it delivered the goods, typically by providing shipping documents confirming the arrival of the goods in the destination country. To cover the risk that the issuing bank will not pay, an exporter may have a bank in its own country confirm the letter of credit, in which case the confirming bank agrees to pay the exporter if the issuing bank defaults.

Documentary collection In contrast to a letter of credit, a documentary collection does not involve payment guarantees. Instead, the exporter's bank forwards shipping/ownership documents to the importer's bank; the documents, which transfer the legal ownership of the traded goods to the importer, are handed to the importer only upon payment for the goods (figure 2).

Because the importer only receives the shipping/ownership documents upon payment, both LCs and DCs increase the probability that the exporter is paid for the delivered goods. However, a letter of credit provides more security to the exporter than does a documentary collection. With a letter of credit, an exporter is paid by the issuing bank/confirming bank upon proof of delivery regardless of whether the importer paid. In contrast, with a documentary collection, the exporter is remunerated only if the bank receives the payment from the importer. If the importer does not want the goods, or can take possession of the goods and divert them without the export documents, the exporter may not get paid even though it delivered.

\footnotetext{
${ }^{12}$ Besides non-delivery and non-payment, there could also be a timing problem. Eventually, the exporter may deliver and the importer may pay, but a long delay would generate significant costs for the other party.
} 


\subsection{The Use of LCs and DCs by U.S. Exporters}

Between 2010 q4 and 2012 q4, 9.6 percent of U.S. goods exports were settled using a letter of credit (a value of $\$ 33.8$ billion) based on data from SWIFT. ${ }^{13}$ The share of exports that involved documentary collections was significantly lower, with an average value of 1.2 percent of U.S. exports. To which extent U.S. exporters use LCs and DCs depends on where they are shipping to. The top panel of figure 3 lists the top 20 U.S. export destinations over the same period and shows, for each country, the value of LC messages and DC messages relative to U.S. goods exports they received. While LCs and DCs are barely employed by exporters shipping to Canada or Mexico, they are very important for exports to China, Korea and India, with the value of letters of credit corresponding to more than 25 percent of U.S. exports. The lower panel of figure 3 further illustrates the large variation in the use of LCs and DCs across countries. ${ }^{14}$ On the left (right), it reports the 10 destinations with the highest ratio of LC (DC) values to U.S. exports. More than 90 percent of U.S. exports to Uganda rely on LCs, while around 10 percent of U.S. exports to Sri Lanka employ DCs. The model developed in the following section explains this variation.

\section{Theory}

In this section, we present a model of payment contract choice, proposing several innovations to the theory in Schmidt-Eisenlohr (2013) and Antràs and Foley (forthcoming). First, we model documentary collections, which have been omitted from the theoretical framework until now. Second, we present a new formulation of the LC contract, modeling key features of this financial instrument that were not accounted for previously. The LC fee is not constant as in Schmidt-Eisenlohr (2013); instead it is a function of the importer's default risk and consists of both a fixed and a variable component. These new features are key for matching the empirical patterns, in particular the hump-shaped relationship between the use of LCs and importer country risk that we document in section 4 .

\footnotetext{
${ }^{13}$ These data are used for the empirical analysis in section 4 . Please see that section for further details on the data.

${ }^{14}$ Note that offshore centers are excluded from the charts. For a list of countries designated as offshore centers, see the data appendix.
} 


\subsection{Model setup}

In the model, one exporter is matched with one importer. They play a one-shot game and have a choice between four payment contract types: cash-in-advance (CIA), open account (OA), documentary collection (DC) and letter of credit (LC). Both firms are risk-neutral. The exporter has all bargaining power and makes a take-it-or-leave-it offer to the importer specifying the payment contract, the price and the quantity of the goods to sell. $R$ denotes the sales value of the goods in the destination country and $K$ the production costs in the source country. $1+r$ and $1+r^{*}$ reflect the financing costs in the source country and the destination country, respectively.

Firms are either good or bad. A good firm always fulfills a contract. A bad firm breaks it whenever doing so is profitable. The share of good firms in the source country is given by $\eta$ and in the destination country by $\eta^{*}$. If a firm does not voluntarily fulfill a contract, its trading partner can attempt to enforce it in court. This is successful in the source country with probability $\lambda$ and in the destination country with probability $\lambda^{*}$.

\subsubsection{Cash-in-advance}

Under cash-in-advance terms, the importer first pays for the goods and then the exporter delivers them. Due to the time delay between the pre-payment and the arrival of the goods at the destination, the importer needs to pre-finance the transaction at its local interest rate $1+r^{*}$, and the exporter receives the payment before incurring the production costs. This gives rise to a commitment problem because the exporter can decide to keep the money without delivering the goods. Exporters that are of the good type (share $\eta$ ) always fulfill the contract, whereas bad exporters (share $1-\eta$ ) always try to get away without producing. If an exporter defaults on the contract, the importer goes to court, which enforces the contract with probability $\lambda$.

The exporter, who has all the bargaining power, takes the enforcement probability $\lambda$ into account and chooses the optimal pre-payment $C^{C I A}$ to maximize its expected profit. ${ }^{15}$ The

\footnotetext{
${ }^{15}$ Two bad-exporter strategies need to be distinguished: pooling and separating. Under pooling, a bad exporter imitates the good exporter. Under separating, it chooses a different strategy that reveals its type. Following Schmidt-Eisenlohr (2013), we assume that conditions are such that only the pooling case arises. This is the case if $\frac{R}{K}>\frac{\left(1+r^{*}\right)}{\eta}$. See appendix B for details and a formal derivation of all results.
} 
exporter also respects the participation constraint of the importer. The expected profit of a good exporter can be derived as:

$$
\mathrm{E}\left[\Pi_{E}^{C I A}\right]=\frac{\eta+(1-\eta) \lambda}{1+r^{*}} R-K
$$

Because the importer pre-finances the transaction, the profitability of cash-in-advance terms decreases with the financing costs in the destination country $1+r^{*}$. Profitability also depends on the degree of contract enforcement $\lambda$ and the share of good firms $\eta$ in the source country. Because the importer bears the risk that goods do not get delivered, the higher are $\lambda$ and $\eta$, the higher is the exporter's expected profit.

\subsubsection{Open account}

With an open account, the exporter first sends the goods and then the importer pays for them. Because the exporter incurs the production costs and delivers the goods to the importer before receiving the payment, the exporter has to pre-finance the working capital at its local interest rate $1+r$. The commitment problem is now on the side of the importer, who may decide not to pay for the goods after receiving them. Good importers (share $\eta^{*}$ ) pay the agreed price in any case, while bad importers (share $1-\eta^{*}$ ) try to get away without paying. When faced with a bad importer, the exporter goes to court, which enforces the contract with probability $\lambda^{*}$.

The exporter maximizes expected profit respecting the participation constraint of the importer, which results in: ${ }^{16}$

$$
\mathrm{E}\left[\Pi_{E}^{O A}\right]=\frac{\eta^{*}+\left(1-\eta^{*}\right) \lambda^{*}}{1+r} R-K
$$

With an open account, pre-financing is done by the exporter. Consequently, higher financing costs in the source country, $1+r$, reduce the exporter's expected profit. Because the commitment problem is on the importer's side, better contract enforcement and a higher share of good firms in the destination country (higher $\lambda^{*}$ and $\eta^{*}$ ) increase the profitability of an open account.

\footnotetext{
${ }^{16}$ Because we focus on the case in which both types of importers participate in trade, the relevant constraint is the participation constraint of good importers. See appendix B for the details.
} 


\subsubsection{Documentary collection}

In a documentary collection transaction (figure 2), banks handle documents that transfer the ownership rights from the seller to the buyer. A DC ensures that the importer receives the documents only after paying for the goods. Because the importer typically needs the documents to fully employ the delivered goods, a DC improves the reliability of payment compared with an open account. ${ }^{17}$

We make two assumptions to capture these features of a documentary collection. First, we assume that with a documentary collection fewer firms try to cheat. More specifically, the share of firms that voluntarily fulfill their contracts increases by a factor of $\phi^{D C} \in\left(0, \frac{1-\eta^{*}}{\eta^{*}}\right)$. Payment then happens with probability $\eta^{*}\left(1+\phi^{D C}\right)+\left(1-\eta^{*}\left(1+\phi^{D C}\right)\right) \lambda^{*}$. More generally, define the probability of payment as a function of $\phi$ as:

$$
\Lambda(\phi)=\eta^{*}(1+\phi)+\left(1-\eta^{*}(1+\phi)\right) \lambda^{*}
$$

Second, the exporter needs to pay a fixed transaction fee $F^{D C}$ to the bank for its handling of the documentary collection. Expected profits are then as follows:

$$
\mathrm{E}\left[\Pi_{E}^{D C}\right]=\frac{\Lambda\left(\phi^{D C}\right)}{1+r} R-F^{D C}-K
$$

Relative to an open account, the exporter's expected profit increases due to the higher probability of being paid. However, the profit is reduced by the fee $F^{D C}$, which the exporter pays at the beginning of the transaction. Note that the fee is not proportional to the value of the trade so that a documentary collection features increasing returns to scale.

\subsubsection{Letter of credit}

When a trade is settled with an LC (figure 1), banks do not only hand over documents to the importer as in a DC but they may also advance the importer's payment. The exporter is paid as soon as it proves that it has delivered the goods. Because banks may incur a loss

\footnotetext{
${ }^{17}$ Even with a DC arrangement, however, the importer may still not pay. For example, when the importer can take possession of the goods and divert them without demonstrating legal ownership. Alternatively, the importer may not pay because it no longer wants the goods or because it simply does not have the funds (for example in bankruptcy). We abstract from the latter case in the analysis here.
} 
if the importer does not pay, they screen importers much more actively when they issue an LC than when they engage in a DC. ${ }^{18}$ Accordingly we assume that the share of importers that try to get away without paying decreases by more with an LC than with a DC. At the same time, the fixed fee that the bank charges for an LC to cover screening, monitoring and document handling costs is higher than for a DC.

Specifically, assume that the share of importers that always pay increases by a factor of $\phi^{L C}>\phi^{D C}$. There remains a risk that the bank does not get paid, which happens with probability $1-\Lambda\left(\phi^{L C}\right)$. The cost that the bank incurs for screening and monitoring is given by $m>F^{D C}$ and is independent of the value of the transaction. ${ }^{19}$ Under perfect competition, banks charge an importer the monitoring cost $m$ plus the expected loss from extending the guarantee. The letter of credit fee is thus given by:

$$
F^{L C}=m+\frac{1-\Lambda\left(\phi^{L C}\right)}{1+r^{*}} C^{L C}
$$

Note that the fee is paid in the first period by the importer while the potential loss arises only after a time delay. Therefore the expected loss is discounted by $1+r^{*}$. The exporter's expected profits with an LC can be derived as:

$$
\Pi^{L C}=\frac{1-(m / R)\left(1+r^{*}\right)}{(1+r)\left[2-\Lambda\left(\phi^{L C}\right)\right]} R-K
$$

Profits with an LC decrease both in the financing costs in the source country and in the destination country, $1+r$ and $1+r^{*}$, since the exporter needs to pre-finance the transaction and the importer needs to pre-finance the LC fee. Because the risk that the exporter does not deliver is eliminated by an LC, expected profits are independent of the enforcement probability $\lambda$. However, profits depend on the enforcement probability $\lambda^{*}$ in the importing country through the fee $F^{L C}$. Recall that the probability $\Lambda(\phi)$ that the importer pays increases in $\lambda^{*}$. Thus, under this payment form, the higher the risk that the importer does not pay, the lower the profits are. As with a DC, the LC case contains an element of increasing returns to scale since the monitoring cost $m$ is fixed. The average cost of an LC decreases in transaction size $R$.

\footnotetext{
${ }^{18}$ Additionally, to reduce the risk that the importer does not pay, banks can require the importer to put down a cash deposit equivalent to the value of the guarantee.

${ }^{19}$ While certainly more realistic, $m>F^{D C}$ also ensures that LCs do not always dominate DCs.
} 
The formulation of the letter of credit fee here is different from that in Schmidt-Eisenlohr (2013) and is arguably more realistic. In that paper, the LC fee is exogenous and proportional to the value of the trade transaction. Here the letter of credit fee consists of a fixed component and a variable component; the latter is a function of the importing country's risk. Although information on the pricing of LCs is not available, we have data on average insurance premia charged by the U.S. Export-Import Bank for export transactions to 29 countries. Figure 4 shows a strong negative relationship between a destination's insurance premium and a measure of its rule of law in the year $2004 .^{20}$ It is likely that the fee for an LC behaves similarly; there is anecdotal evidence that the fee of an LC indeed increases with the riskiness of the issuing bank and the riskiness of the importing country. ${ }^{21}$

Before formally deriving the new predictions of the model, it is useful to summarize the key trade-offs exporters and importers face when choosing a payment contract. Each of the payment forms varies in terms of how the risk and the financial burden are allocated between trading partners as well as in the levels of risk and costs they imply. Table 1 summarizes the trade-offs. CIA terms allocate all the risk and all the financing costs to the importer. With an open account, the exporter bears both the risk and the financial costs. A DC reduces the risk for the exporter but increases its costs due to the document handling fee. An LC eliminates the risk for both the importer and the exporter, but the financial costs increase substantially because the bank has to be compensated for the guarantee it extends and for the administrative costs that arise. In the following section, we focus on contract enforcement in the importing country and analyze in detail how it affects the payment contract choice.

\subsection{Trade finance and destination country risk}

Proposition 1 states how expected profits under each payment contract change with the probability $\lambda^{*}$ that a contract is enforced in the destination country.

Proposition 1 Expected profits from cash-in-advance, an open account, a documentary collection and a letter of credit change in destination country enforcement $\lambda^{*}$ in the following

\footnotetext{
${ }^{20}$ The data on insurance premia were first used in Hale et al. (2013). Information on rule of law is from the World Banks' World Government Indicators.

${ }^{21}$ See, for example, http://opentoexport.com/article/a-guide-to-letter-of-credit-charges/. The cost of an LC consists of a fixed fee that covers banks' administrative costs and additional charges proportional to the value of the transaction and the validity period of the LC.
} 
way:

$$
\frac{\partial E\left[\Pi^{O A}\right]}{\partial \lambda^{*}}>\frac{\partial E\left[\Pi^{D C}\right]}{\partial \lambda^{*}}>\frac{\partial E\left[\Pi^{L C}\right]}{\partial \lambda^{*}}>\frac{\partial E\left[\Pi^{C I A}\right]}{\partial \lambda^{*}}=0 .
$$

\section{Proof. See appendix A.}

Corollary 1 follows directly from proposition $1:^{22}$

Corollary 1 Suppose that each contract type $C \in\{C I A, O A, D C, L C\}$ is used for some $\lambda^{*} \in[0,1]$. Then, there exist $\bar{\lambda}_{3}^{*}>\bar{\lambda}_{2}^{*}>\bar{\lambda}_{1}^{*}$, such that:

- (i) Cash-in-advance is used if $\lambda^{*} \leq \bar{\lambda}_{1}^{*}$.

- (ii) A letter of credit is used if $\lambda^{*} \in\left(\bar{\lambda}_{1}^{*}, \bar{\lambda}_{2}^{*}\right)$.

- (iii) A documentary collection is used if $\lambda^{*} \in\left[\bar{\lambda}_{2}^{*}, \bar{\lambda}_{3}^{*}\right)$.

- (iv) An open account is used if $\lambda^{*} \geq \bar{\lambda}_{3}^{*}$.

Proof. Follows immediately from proposition 1.

Figure 5 illustrates the findings of proposition 1 and corollary 1. It shows exporter profits under each payment form as a function of the probability $\lambda^{*}$ that a contract is enforced in the destination country. Proposition 1 is about the ordering of the slopes of the curves in figure 5, which is unique. To understand the ordering, recall that under each payment contract the exporter is differently exposed to the risk that the importer does not pay. The higher the exporter's exposure, the larger is the effect of a change in the probability $\lambda^{*}$ on expected profits, and the steeper is the profit line in the figure. An open account allocates all the risk to the exporter. Profits under this payment form therefore respond the most to changes in $\lambda^{*}$. Since a documentary collection and a letter of credit reduce the risk that the importer gets away without paying, expected profits with an LC or a DC are less responsive to changes in $\lambda^{*}$. When the trade is settled on cash-in-advance terms, the commitment problem on the importer's side is eliminated, so CIA profits are independent of the degree of contract enforcement in the destination country, resulting in a flat line in the figure.

\footnotetext{
${ }^{22}$ Assume, without loss of generality, that if indifferent between multiple payment contracts, an exporter chooses in the following order: OA, CIA, DC, LC.
} 
The unique ordering of the slopes implies that if each payment contract is optimal for some value of $\lambda^{*} \in[0,1]$, then CIA is chosen for the lowest values of contract enforcement that is for all $\lambda^{*} \leq \lambda_{1}^{*}$. As the probability that a contract is enforced rises, first LCs dominate (for $\lambda^{*} \in\left[\lambda_{1}^{*}, \lambda_{2}^{*}\right]$ ), then DCs (for $\lambda^{*} \in\left[\lambda_{2}^{*}, \lambda_{3}^{*}\right]$ ). An open account is optimal when the risk that the importer does not pay is low, that is when $\lambda^{*} \geq \lambda_{3}^{*}$.

Figure 5 illustrates that firms rely on banks to settle their payments when the degree of contract enforcement in the destination country is neither too low nor too high. Figure 6 shows how much better is the profitability of LCs and DCs in this range relative to the other payment forms. The graph plots the difference between profits from an LC and its best alternative (dotted line) and the difference between profits from a DC and its best alternative (solid line). Each of the two lines exhibits a kink. The kink is at the value of $\lambda^{*}$ at which a firm is indifferent between its two second-best alternatives. At the kink of the LC line $\left(\lambda^{*}=\lambda_{L C}^{*}\right)$, expected profits from cash-in-advance and documentary credit are equal. At the kink of the DC line $\left(\lambda^{*}=\lambda_{D C}^{*}\right)$, an LC and an open account imply the same expected profits.

To build intuition for the kinks, focus on the LC line. The higher the contract enforcement $\lambda^{*}$ in the destination country, the more profitable are LCs compared with cash-in-advance terms. At the same time, at any point, a higher $\lambda^{*}$ implies a lower profitability of LCs relative to DCs. Moving from the left to the right in the graph, the relative profitability of an LC therefore increases compared with cash-in-advance terms but decreases compared with a DC. The maximum distance between the expected profits of an LC and its alternatives is therefore reached when an exporter is indifferent between cash-in-advance terms and a DC.

In the baseline model, where all firms face exactly the same decision, changes in the profitability advantage of a payment form do not matter. Firms always choose the most profitable contract, independently of the profitability of any alternatives. However, the relative profitability of a payment form matters when we want to take the model to the data. To illustrate this point, we simulate an extended version of the model. Assume now that there is a continuum of exporters and importers in the source and the destination country. Each exporter draws a random, multiplicative shock to the profitability of each payment form that captures its idiosyncratic business circumstances. With a sufficiently large support of the shock distribution, there is always an exporter that is indifferent between an LC (DC) 
and an alternative payment method when trading with an importer in a given destination country. $^{23}$ As a consequence, the share of exporters that use LCs (DCs) increases with the relative profitability of LCs (DCs), which is highest for intermediate values of contract enforcement. Therefore the relationship between the share of exporters that use LCs (DCs) and contract enforcement $\lambda^{*}$ in the destination country is hump-shaped.

Figure 7 shows the share of exporters that use each payment form in a simulated example. ${ }^{24}$ Contract enforcement $\lambda^{*}$ in the destination country is on the $x$-axis. In line with the intuition developed earlier, the share of exporters that offer cash-in-advance terms decreases with the degree of contract enforcement in the destination while the share of exporters that settle payments on an open account increases. There is a clear hump-shaped relationship between the use of LCs (DCs) and $\lambda^{*}$. The DC curve lies to the right of the LC curve, which implies that the share of exports that are settled with LCs peaks at a lower level of contract enforcement than the share of exports that rely on DCs. We show in the next section that these are exactly the patterns that we observe in the data. ${ }^{25}$

\subsection{Trade finance and transaction size}

In the model, DCs and LCs imply fixed document handling, screening and monitoring costs. These give rise to increasing returns to scale. Therefore, the higher the value of a contract is, the more attractive DCs and LCs become. Let production cost $K$ be a constant fraction of revenues $R$, that is $K=\gamma R$. Then, the following proposition can be derived:

Proposition 2 Suppose that each contract type $C \in\{O A, D C, L C\}$ (or $C \in\{C I A, D C, L C\})$ is used for some $R$. Then, there exist $\bar{R}_{2}>\bar{R}_{1}$, such that:

- (i) An open account (or cash-in-advance) is used if $R \leq \bar{R}_{1}$.

\footnotetext{
${ }^{23}$ Any single-peaked distribution with mean zero and a sufficiently large support can be used.

${ }^{24}$ Parameter values are: $\eta=\eta^{*}=0.75, \lambda=0.8, R=1.5, K=1, r^{*}=r=0.05, f^{D C}=0.5 \%, m=5 \%$, $\lambda^{*} \in[0.3,1], \phi^{D C}=0.05$ and $\phi^{L C}=0.2$. The shocks to the profitability of the four contracts are assumed to be independently normally distributed with variance 0.1 and mean 1 .

${ }^{25}$ Instead of four individual shocks to the profitability of each payment form, we can also introduce exporterimporter-pair specific shocks to the strength of contract enforcement in the source country and in the destination country. While the shocks underlying the simulations imply that the profitability of the different contracts varies across firms, shocks to $\lambda$ and $\lambda^{*}$ allow for differences in the degree to which exporters and importers can enforce contracts. The hump shapes also result under this alternative formulation of the shocks.
} 
- (ii) A documentary collection is used if $R \in\left[\bar{R}_{1}, \bar{R}_{2}\right]$.

- (iii) A letter of credit is used if $R>\bar{R}_{2}$.

Proof. See appendix A.

The model predicts that for small transaction sizes (low $R$ ), firms should rely on an open account or cash-in-advance terms to save on fixed costs. Transactions with intermediate values should be settled with documentary collections. When transactions are very large, letters of credit are most attractive; they imply the highest fixed costs but at the same time reduce payment risk the most. The trade-off between CIA and OA is independent of $R$.

\section{Empirical Analysis}

In this section, we conduct a regression analysis to systematically explore the relationship between country risk and the use of LCs and DCs for exporting. According to the theory, firms should rely the most on banks to facilitate international trade when shipping to countries with intermediate degrees of contract enforcement. In addition, letters of credit should be employed more than documentary collections by exporters that sell to riskier destinations. The theory also states that the size of a trade transaction affects the profitability of the different payment contracts. We show that these model predictions are strongly supported by the data. We also investigate the role of geographical distance for firms' choices.

\subsection{Data Sources}

The main data set comes from SWIFT (the Society for Worldwide Interbank Financial Telecommunication). The SWIFT network provides a communications platform through which financial institutions exchange standardized financial messages. According to the SWIFT website, more than 10,500 corporations and financial institutions in 215 countries use this platform. SWIFT estimates that, worldwide, about 90 percent of LC and DC transactions go through the SWIFT network, but this number is likely much higher for U.S. activity since practically all banks in the United States use this service. Whenever a bank in an importing country issues a letter of credit, it sends a so-called MT700 message to the U.S. 
bank involved; when it releases a payment related to a documentary collection, it sends an MT400 message to the U.S. bank. The message specifies the terms of the letter of credit or the payment, including the names of the trading parties, the banks involved and the goods traded. Our SWIFT data set shows the number of MT700 and MT400 messages received by banks located in the United States by sender country at a monthly frequency from 2003 to 2012. From the fourth quarter of 2010 onward, we also know the total value of the messages in dollars. Because the value data is available for only a relatively short period, and message counts and amounts are highly correlated, we mainly use the count data for the analysis. ${ }^{26}$

In addition to data from SWIFT, we also employ information from the Country Exposure Reports (FFIEC 009) collected by the Federal Reserve Board on U.S. banks' trade finance claims. These claims reflect mostly letters of credit in support of U.S. exports, and we employ them to show the robustness of our results regarding the use of LCs. ${ }^{27}$ Quarterly U.S. exports data is from the IMF Directions of Trade Statistics. ${ }^{28}$ Since most of the dependent variables used in the regression analysis only vary at an annual frequency, we sum the data over four quarters and run regressions on yearly data. A complete list of variables and data sources can be found in appendix $\mathrm{C}$.

\subsection{The effect of destination country risk}

To test for the effect of destination country risk on the choice of payment contract, we estimate the following equation:

$$
\begin{aligned}
& \log \left(Y_{c t}\right)=\beta_{1} \log \left(\exp _{c t}\right)+\beta_{2} \log \left(\text { distance }_{c}\right)+\beta_{3} \operatorname{law}_{c t}+\beta_{4}\left(\operatorname{law}_{c t}\right)^{2} \\
& +\beta_{5} \log (\text { GDP per capita } \text { ct })+\beta_{6}\left(\text { GDP per capita }{ }_{c t}\right)^{2} \\
& +\beta_{7} \log \left(\text { fin. development }{ }_{c t}\right)+\beta_{8} \text { LC requirement dummy }{ }_{c t}+\alpha_{t}+\epsilon_{c t},
\end{aligned}
$$

\footnotetext{
${ }^{26}$ The correlation between $\log$ values and $\log$ numbers is about 90 percent.

${ }^{27}$ For a more detailed discussion of the FFIEC 009 data, see appendix D and an earlier working paper version of this research (Niepmann and Schmidt-Eisenlohr (2013a)).

${ }^{28}$ To account for the fact that, for data from 2003 to 2010 , we observe only the number of SWIFT messages, not the associated values, we experimented with information on cards from the Census Bureau instead of export values as a control variable. A card reflects an HS 10-digit line item within a shipment. Log cards and export values show a correlation of 0.96 , so we use only export values.
} 
where $Y_{c t}$ stands either for the number of LC or DC messages sent to banks in the United States. The dependent variables are regressed on the log of exports, on the log of distance, and on a measure of the degree to which contracts are enforced in destination $c$ denoted by $l a w_{c t}$. We use as a proxy for contract enforceability the rule of law index from the World Bank's World Governance Indicators. Since the index takes negative values for some countries, it is mapped on the interval between 0 and 1 , where 1 corresponds to the highest degree of the rule of law observed. ${ }^{29}$ We also include rule of law squared in equation (7) to allow for the non-linear relationship predicted by the theory. As the quadratic specification may seem restrictive, we show in section 6.4 that a semi-parametric estimation that allows for an entirely flexible form delivers very similar results.

According to the model, interest rates should affect firms' choices of payment contracts. We therefore control for the importing country's stage of financial development in the regressions. In line with the extensive literature on the topic, we measure financial development by the variable private credit by financial institutions over GDP taken from the World Bank's Financial Structure Database. ${ }^{30}$ Because there are countries that require firms to use LCs when trading internationally, we include a dummy variable that takes the value of 1 when such a requirement is in place in country $c$ at time $t .^{31}$ GDP per capita and GDP per capita squared are also added as regressors to ensure that the effect of contract enforceability is not due to omitted factors that are correlated with a country's overall development. Moreover, all regressions control for time fixed effects. Standard errors are clustered by country.

Table 2 presents the results. Column (1) shows the relationship between letters of credit sent to the U.S. and the degree of contract enforcement in the importing country. The coefficient of the linear rule of law term is positive while the coefficient of the squared term is negative. Both coefficients are highly significant. They indicate a non-linear relationship between a destination's rule of law and the use of letters of credit in U.S. exports. That is, controlling for other factors, letters of credit are used the most for exports to countries with intermediate levels of risk, a finding consistent with the predictions of the theory.

The relationship is quantitatively relevant. To see this, consider the following example based on the point estimates in column (1): if Guatemala (normalized rule of law of 0.28)

\footnotetext{
${ }^{29}$ The mapping is done through a simple linear transformation, where law $w_{\text {new }}=\frac{\text { law } w_{\text {old }}-\min \left(\text { law } w_{\text {old }}\right)}{\max \left(\text { law }_{\text {old }}\right)-\min \left(\text { law } w_{\text {old }}\right)}$.

${ }^{30}$ See, for example, Beck (2003), Manova (2013).

${ }^{31}$ Information on countries' documentation requirements is from the IMF's AREAER Database.
} 
had the same rule of law as Brazil (normalized rule of law of 0.51 in 2012), the trade finance claims of U.S. banks would increase by 25.8 percent. In contrast, if Brazil had the same rule of law as Israel (normalized rule of law of 0.75 in 2012), trade finance claims toward Brazil would decline by 21.7 percent. The moves from Guatemala to Brazil and from Brazil to Israel correspond to roughly one standard deviation of the rule of law index. Thus, the magnitudes are economically significant.

Note also that the coefficient of financial development is highly significant and positive. This indicates that LCs are used more for exports to more financially developed countries. ${ }^{32}$

According to the theory, the use of DCs in international trade should also be humpshaped in destination country risk. This prediction is tested in column (2) of table 2, which shows results for the number of DC messages. The coefficients of rule of law and rule of law squared are again highly significant, with the linear term being positive and the quadratic term being negative as expected. Compared to the results for the number of LC messages in column (1), the estimated coefficient associated with the linear rule of law term is much larger.

To further explore differences in the relationship between the use of DCs and LCs and a country's rule of law, we estimate the following pooled regression:

$$
\begin{aligned}
\log \left(Y_{m c t}\right) & =\beta_{1} \log \left(\exp _{c t}\right)+\beta_{2} \log \left(\text { distance }_{c}\right)+\beta_{3} \operatorname{law}_{c t}+\beta_{4}\left(\operatorname{law}_{c t}\right)^{2} \\
& +\beta_{5} \mathrm{DC} \text { message dummy } \operatorname{lum}_{m c t}+\beta_{6} \operatorname{law}_{c t} \times \text { DC message dummy } \text { met }_{m}+ \\
& +\beta_{7}\left(\operatorname{law}_{c t}\right)^{2} \times \text { DC message dummy }{ }_{m c t}+\beta_{8} \log \left(X_{c t}\right)+\alpha_{t}+\epsilon_{c t} .
\end{aligned}
$$

Now $\log \left(Y_{m c t}\right)$ stands for the number of messages of type $m$ received by U.S. banks from country $c$ in year $t . X_{c t}$ collects additional control variables. The regression includes a dummy that takes the value of 1 if the message refers to a documentary collection and zero if the message is related to a letter of credit as well as interactions between the dummy and the rule of law variables.

\footnotetext{
${ }^{32}$ The model does not predict the sign of this coefficient. One would typically expect financing costs to decrease in financial development. While an increase in the destination country financing costs improves the relative profitability of LCs compared with cash-in-advance, it reduces relative profitability compared with open account. The positive correlation between financial development and LC use may arise because the number of potential correspondent banks is likely to be increasing in destination country financial development. This channel is, however, outside the scope of the model presented here.
} 
Column (3) of table 2 confirms that the coefficient of the linear term is significantly different for DCs and LCs, being twice as large for DCs. ${ }^{33}$ Figure 8 illustrates what this means. It shows the relationship between the use of LCs and DCs, respectively, and the rule of law index based on the results in column (3). The use of LCs in U.S. exports first rises and then falls with a destination's rule of law, with a peak at a value of 0.49 , which is equivalent to Morocco's rule of law index in $2012 .{ }^{34}$ In contrast, the use of DCs largely increases with a country's rule of law. The relationship is concave implying that an improvement in the degree to which a contract can be enforced in the destination has a larger positive effect on the use of DCs when contract enforceability is low. The share of exporters that use DCs is highest for a rule of law index of 0.92, which corresponds to Germany's index in 2012. Thus the use of DCs in exports reaches its maximum at a higher value of contract enforceability than the use of LCs. Exactly this pattern is predicted by the theory (see again corollary 1 and figure 7).

Next, we present a more direct way to test whether LCs are used more for exports to riskier destinations than DCs. We compute the share of LC messages in total SWIFT messages $(\mathrm{LC}+\mathrm{DC})$ to destination $c$ in year $t$ and regress this variable on the rule of law index and other controls. Regression results are presented in table 3. Column (1) includes only the rule of law index as an explanatory variable. This regressor alone explains 37.5 percent of the variation in the share of LC messages in total messages. The highly significant, negative coefficient indicates that the share of LCs decreases as the ability to enforce a contract in the importing country increases. Column (2) shows that this result is robust to the inclusion of other country variables as well as time fixed effects, which interestingly add hardly any explanatory power. ${ }^{35}$

\subsection{The effect of distance}

All regressions in the previous section controlled for the distance of an export destination from the United States and indicated a strong positive relationship between the use of letters

\footnotetext{
${ }^{33}$ When an additional interaction between rule of law squared and the message type is included, we find that the coefficient on the quadratic term is the same for both message types.

${ }^{34}$ The mean rule of law in the sample is 0.55 .

${ }^{35}$ When rule of law squared is added as a regressor, its coefficient is insignificant, which suggests that the share of LC messages indeed decreases linearly with the rule of law index.
} 
of credit (documentary collections) and this variable. In this section, we explore the link between distance, contract enforceability and payment contract choice in more detail. ${ }^{36}$

The risk of transactions and therefore firms' incentives to use LCs and DCs could be increasing with the distance between trading partners for several reasons. First, it is probably harder to communicate and to litigate a contract dispute when the trading partner is far away. Second, it may be more difficult to thoroughly screen foreign sellers and buyers. ${ }^{37}$ Finally, long shipping times may increase the risk that the importer will no longer want the traded goods or will go bankrupt before the transaction is completed.

Results in table 2 are consistent with the view that long-distance trade is riskier. The distance coefficient is positive and highly significant in all columns. Since there is no mechanical link between the number of LC transactions and distance, the positive effect is a strong indicator that distance magnifies the risks inherent in international trade transactions.

To test further for differences in the relationship between contract enforceability and payment contract choice across export destinations, we run regressions on the full sample and introduce a dummy variable that takes value 1 if a country has an above-median distance from the United States and zero otherwise. The dummy is interacted with rule of law and rule of law squared. Columns (4) and (5) of table 2 report the results and figures 9 illustrates them. Based on the estimated coefficients, the dotted lines in both panels show how the use of bank-intermediated trade finance changes with a country's rule of law when destinations are close to the United States. The dashed line depicts the relationship when countries are far away. Consider first the top chart, which plots the relationship for LCs. The use of LCs in exports to countries close to the United States appears to fall with a destination's rule of law. This relationship is not statistically significant, however. ${ }^{38}$ In contrast, there is a strong hump-shaped relationship between the use of LCs and payment risk for long-distance destinations. Proximity appears to mitigate risk. Results are different for documentary collections, as the bottom panel shows. Regardless of whether importers are close to or far from the United States, the use of DCs rises with the ease of enforcing contracts. Note also

\footnotetext{
${ }^{36}$ Schmidt-Eisenlohr (2013), Bourgeon et al. (2012), and Paravisini et al. (forthcoming) investigate how distance affects the response of trade to changes in financial conditions. Also related is Berman et al. (2012), who study how distance influences the adverse effects of financial crisis on trade.

${ }^{37}$ For example, Krautheim (2012) shows theoretically that obtainable information should decline in distance because learning through networks gets weaker.

${ }^{38}$ When regressions do not include the log of GDP per capita squared, the relationship between the use of LCs and destination country risk is essentially flat for destinations close to the U.S.
} 
that the elasticity of the number of SWIFT messages with respect to log distance is larger for DCs than for LCs (see again table 2). Therefore, LCs appear to be central in the mitigation of payment risk; DCs seem to be particularly relevant for addressing risks that arise from long transport routes. We conclude that longer geographic distances are associated with greater risks, making the use of letters of credit and documentary collections more desirable.

\subsection{Transaction size}

Importers and exporters have to pay a fee for LCs and DCs. Because a part of the fee is fixed (covering document handling, screening and monitoring costs), the attractiveness of these payment forms increases with the size of an export transaction. Proposition 2 predicts that the largest transactions should be settled with letters of credit. Transactions with intermediate values should rely to a greater extent on documentary collections. Smaller transactions, in contrast, should be conducted through cash-in-advance terms or an open account.

While we do not observe the transaction value for single letters of credit and documentary collections, we can use the SWIFT data to study the average size of LC and DC transactions in the aggregate and by country. We have information on both the total value of LCs and DCs and on the corresponding number of SWIFT messages sent by importing country. In addition, we know the total value of U.S. exports to a destination and the number of shipments (Census Bureau cards) so we can compare the average size of LC and DC transactions to the average value of an export transaction.

In a first step, we calculate the average transaction size of letters of credit, documentary collections and aggregate trade for the period in which SWIFT value data are available, that is, from $2010 \mathrm{q} 4$ to $2012 \mathrm{q}^{3} .^{39}$ In this period, the average value of an LC is $\$ 716.2$ thousand. The average value of a DC is $\$ 138.7$ thousand. For all trade transactions, the average value is $\$ 42.7$ thousand. ${ }^{40}$ Thus, an average LC transaction is more than sixteen times as large as an average trade transaction, while an average DC transaction is more than three times as

\footnotetext{
${ }^{39}$ To compare transaction sizes across payment types, we restrict the sample to countries for which each payment type is observed. This reduces the number of countries to 84 . Results are basically identical when we calculate the numbers for the unbalanced data set with over 184 countries.

${ }^{40}$ We can also calculate the average value of trade transactions that are neither LC nor DC. For this, we first deduct the value (number) of LCs and DCs, respectively, from the total export value (number of shipments). The average value of the remaining transactions then falls to $\$ 39.2$ thousand.
} 
large.

One may be concerned that this ranking is driven by countries with particularly large LC transactions. To account for this possibility, we also calculate average transaction sizes by country. Figure 10 presents kernel density estimates of the log of the average transaction value of LCs, DCs and aggregate exports. Each curve is based on 84 country observations. The LC density is clearly to the right of the DC density, which is to the right of the density for all transactions, in line with the model predictions.

As a final check, we compute the share of countries for which the ordering of transaction sizes is consistent with the theory. Table 4 summarizes the results. There are 84 countries with positive DC, LC and export values and numbers. For 92.9 percent of these countries, LCs have a higher average value than DCs. For 95.2 percent of the countries, LCs have a higher average value than other trade transactions, and for 78.6 percent of the countries, DCs are on average larger than other trade transactions. These numbers increase to 97.6, 100 and 90.5 percent, respectively, when we focus exclusively on countries with above median average exports. In other words, when we abstract from measurement error in smaller countries, LC transactions are always the largest, followed by DCs. Transactions that use neither LCs nor DCs are the smallest. These results support our modeling assumptions and suggest that LCs and DCs involve substantial fixed costs.

\subsection{Robustness}

In this section, we present robustness checks, which show that our results to do not change when we add dummies for continents or specific countries in which the use of LCs may be historically high. Results are very similar when we semi-parametrically estimate the relationship between the use of LCs, DCs and a country's rule of law. We also address concerns of endogeneity and employ alternative proxies for contract enforceability in the destination country. Finally, we add more control variables to the regressions and show that results remain the same when proxying LC use by U.S. banks' trade finance claims obtained from the Country Exposure Report (FFIEC 009) collected by the Federal Reserve Board. 
Continent, China, India and South Korea dummies The skeptical reader may be concerned that the documented patterns are driven by certain regions or countries that for historical or other reasons employ LCs and DCs more intensively than others. Ideally, one would therefore like to include country fixed effects in the regressions. Due to very limited variation over time in countries' rule of law, the inclusion of country fixed effects results in large standard errors. Instead of including a full set of country fixed effects, we therefore add continent dummies as well as dummies for India, China and South Korea to the regressions. The results are reported in table 5. All coefficients are very similar to the baseline results.

Semi-parametric estimation To check that our finding of a hump-shaped relationship between the use of LCs and country risk is not due to the quadratic form assumed before, we estimate the relationship semi-parametrically. We allow for an entire flexible functional form, employing Robinson's (1988) double residual estimator. Log distance, log exports, log financial development, log GDP per capita, and log GDP per capita squared and the dummy for an LC requirement enter the regression linearly. Rule of law enters non-linearly. Precisely:

$$
\log \left(Y_{c t}\right)=\alpha+\beta^{\prime} X_{c t}+f\left(l a w_{c t}\right)+\epsilon_{c t}
$$

where $X_{c t}$ denotes the control variables listed before. Given the results presented in section 4.2, we estimate equation (10) for countries that are above the median distance from the United States separately from those that are below the median. The results are shown in figure 11. The panels on the left (right) are for countries that are far from (close to) the United States. In line with the earlier findings, the top panel shows that the use of LCs does not respond much to changes in country risk when trading partners are close. In contrast, a clearly hump-shaped relationship between the use of LCs and a destination's rule of law emerges for countries with long distances from the United States. Our findings on the use of DCs in exporting are also confirmed. The two bottom charts of figure 11 show that the use of DCs increases with a country's rule of law and that this relationship holds for destinations both close to and far from the United States. 
Ratios as dependent variables One might be worried that U.S. exports are correlated with unobserved factors that also affect firms' choices of payment contracts, which would generate an endogeneity problem. To address this concern, we normalize the left-hand-side variables by dividing the number of LC (DC) messages by the number of shipments; the new dependent variables reflect the share of U.S. exports to destinations that use LCs and DCs, respectively. These are regressed on the various explanatory variables as before. Results are presented in columns (1) and (2) of table 6. While the normalizations naturally change the magnitudes of the coefficients, the results imply the same qualitative relationships as before.

Alternative measures of contract enforcement While the variable for rule of law from the World Bank's World Governance Indicators is widely used as a proxy for the degree to which contracts can be enforced in a country, we show that results also hold when we replace this variable with an alternative measure of country risk. For this, we employ a measure of investor protection from the World Bank's Doing Business Indicators. Regressions in columns (3) and (4) of table 6 are based on this measure. Column (3) confirms that the use of LCs is hump-shaped in the degree of investor protection. The coefficient of investor protection in column (4) that show the results for DCs is positive, in line with our earlier findings, but not significant at standard significance levels.

Columns (5) and (6) of table 6 include dummy variables that control for whether a destination country has the same legal origin as the United States, shares a border with the United States or had a common colonizer. The addition of these variables does not affect the results. $^{41}$

Alternative trade finance measure The Country Exposure Reports (FFIEC 009) collected by the Federal Reserve Bank provide information on the trade finance related claims of all large U.S. banks by destination country. As we discuss in appendix D and an earlier version of this paper (Niepmann and Schmidt-Eisenlohr (2013a)) in more detail, banks' trade finance claims mostly represent letters of credit and similar guarantees in support of U.S. exports. We therefore check whether the same patterns regarding the use of LCs in U.S. exports emerge when we regress banks' trade finance claims on country risk and various other

\footnotetext{
${ }^{41}$ We also experimented with several other control variables, for example, with a dummy for common language. The associated coefficients were always insignificant.
} 
control variables. The results are reported in table 7. Column (1) replicates the baseline regression. Column (2) tests for the differential effect of country risk on the U.S. of LCs for countries with above and below average distance from the U.S. In column (3), trade finance claims over U.S. exports is the dependent variable. In column (4), contract enforceability is proxied by investor protection and in column (6), additional controls variable are included that were discussed in the beginning of the robustness section. All results hold when trade finance claims are used as the dependent variable instead of the number of LC messages. Together the robustness checks shows that the documented empirical patterns are strong features of the data.

\section{Conclusions}

This paper studies the payment contract choice of firms in international trade. Using data from SWIFT, it explores the extent to which U.S. exporters use letters of credit and documentary collections to protect their interest when shipping to foreign markets. We find that their use principally depends on the degree to which contracts are enforced in the destination country and on how far the country is from the United States. Notably, more than 50 percent of U.S. shipments to some destinations are settled with LCs. We present a model that explains the trade-offs for firms when they choose between different payment contracts, and we demonstrate that the model is fully consistent with the patterns in the data. The presented findings have several implications for ongoing discussions around trade finance. First, since letters of credit are used heavily for some destinations, increases in the cost of trade finance that may come from increased due diligence requirements and new rules on capital and leverage have the potential to impact real economic activity not only in the United States but also abroad. The results on the role of distance for the use of trade finance products suggest that the effects would be stronger for long-distance trade. Second, policymakers have interpreted the low usage of trade finance for shipments to less-developed economies as evidence of a gap in the provision of trade finance by commercial banks. ${ }^{42}$ Our theory shows that there are other reasons why LCs may be used little for such destinations, which present a relatively high risk of non-payment by importers. The high risk means that LCs for these countries are

\footnotetext{
${ }^{42}$ There are ongoing discussions at the WTO whether the private sector is able to meet the demand for trade finance, especially in poor countries (see Working Group on Trade, Debt and Finance (2014)).
} 
expensive, and firms may optimally decide to use cash-in-advance terms instead of an LC. ${ }^{43}$ The relative importance of supply and demand factors cannot be disentangled in our data, but it is crucial to distinguish between them for policy interventions. A further exploration of which firms, industries and countries are especially constrained in their access to bank guarantees and other trade finance instruments is a key question for future research.

\section{References}

Ahn, JaeBin, "A Theory of Domestic and International Trade Finance," IMF Working Papers 11/262, International Monetary Fund November 2011.

_ , "Estimating the Direct Impact of Bank Liquidity Shocks on the Real Economy: Evidence from Letter-of-Credit Import Transactions in Colombia," 2013. mimeo.

_, "Understanding Trade Finance: Theory and Evidence from Transaction-level Data," May 2014. International Monetary Fund, mimeo.

Amiti, Mary and David E. Weinstein, "Exports and Financial Shocks," The Quarterly Journal of Economics, 2011, 126 (4), 1841-1877.

Antràs, Pol and C. Fritz Foley, "Poultry in Motion: A Study of International Trade Finance Practices," Journal of Political Economy, forthcoming.

\section{Asmundson, Irena, Thomas William Dorsey, Armine Khachatryan, Ioana Nicul-} cea, and Mika Saito, "Trade and trade finance in the 2008-09 financial crisis," Technical Report 2011.

Beck, Thorsten, "Financial Dependence and International Trade," Review of International Economics, May 2003, 11 (2), 296-316.

_, Asli Demirguc-Kunt, and Ross Levine, "Financial institutions and markets across countries and over time - data and analysis," Policy Research Working Paper Series 4943, The World Bank May 2009.

\footnotetext{
${ }^{43}$ To the extent that high-risk countries have less developed financial markets and local banks charge higher interest rates, the choice of cash-in-advance may be less feasible (because higher interest rates in the importing country make cash-in-advance terms more costly).
} 
Berman, Nicolas, Jos de Sousa, Philippe Martin, and Thierry Mayer, "Time to ship during financial crises," CEPR Discussion Papers 9089, C.E.P.R. August 2012.

Biais, Bruno and Christian Gollier, "Trade Credit and Credit Rationing," Review of Financial Studies, 1997, 10 (4), 903-37.

Bourgeon, Pauline, Jean-Charles Bricongne, and Guillaume Gaulier, "Do Financial Frictions and Trading Time matter for trade? Evidence from French firms," 2012. mimeo.

Burkart, Mike and Tore Ellingsen, "In-Kind Finance: A Theory of Trade Credit," American Economic Review, June 2004, 94 (3), 569-590.

Cunat, Vicente, "Trade Credit: Suppliers as Debt Collectors and Insurance Providers," The Review of Financial Studies, 2007, 20 (2), 491-527.

Demir, Banu and Beata Javorcik, "Grin and Bear It: Producer-Financed Exports from an Emerging Market," 2014. mimeo, University of Oxford and Bilkent University.

Eck, Katharina, Martina Engemann, and Monika Schnitzer, "How trade credits foster exporting," Review of World Economics, 2014, pp. 1-29.

Ferris, J Stephen, "A transactions theory of trade credit use," The Quarterly Journal of Economics, 1981, pp. 243-270.

Giannetti, Mariassunta, Mike Burkart, and Tore Ellingsen, "What You Sell Is What You Lend? Explaining Trade Credit Contracts," Review of Financial Studies, 2011, 24 (4), 1261-1298.

Glady, Nicolas and Jacques Potin, "Bank Intermediation and Default Risk in International Trade-Theory and Evidence," 2011. ESSEC Business School, mimeo.

Hale, Galina, Christopher Candelaria, Julian Caballero, and Sergey Borisov, "Bank Linkages and International Trade," Technical Report, Federal Reserve Bank of San Francisco 2013.

Hoefele, Andreas, Tim Schmidt-Eisenlohr, and Zhihong Yu, "Payment Choice in International Trade: Theory and Evidence from Cross-country Firm Level Data," CESifo Working Paper Series 43502013. 
ICC, "Global Risks - Trade Finance Report 2013," Technical Report, International Chamber of Commerce April 2013.

IFC, "Global Trade Finance Program Brochure," Technical Report, International Finance Corporation January 2012.

IMF, "Survey Among Banks Assessing Current Trade Finance Environment," IMF-BAFT Trade Finance Survey, International Monetary Fund 2009.

Klapper, Leora, Luc Laeven, and Raghuram Rajan, "Trade credit contracts," Review of Financial Studies, 2012, 25 (3), 838-867.

Krautheim, Sebastian, "Heterogeneous firms, exporter networks and the effect of distance on international trade," Journal of International Economics, 2012, 87 (1), 27-35.

Love, Inessa, Lorenzo A Preve, and Virginia Sarria-Allende, "Trade credit and bank credit: Evidence from recent financial crises," Journal of Financial Economics, 2007, 83 (2), 453-469.

Manova, Kalina, "Credit constraints, heterogeneous firms, and international trade," The Review of Economic Studies, 2013, 80 (2), 711-744.

Mayer, Thierry and Soledad Zignago, "Market Access in Global and Regional Trade," Working Papers 2005-02, CEPII research center January 2005.

Ng, Chee K, Janet Kiholm Smith, and Richard L Smith, "Evidence on the determinants of credit terms used in interfirm trade," The Journal of Finance, 1999, 54 (3), 1109-1129.

Niepmann, Friederike and Tim Schmidt-Eisenlohr, "International Trade, Risk, and the Role of Banks," Staff Reports 633, Federal Reserve Bank of New York September 2013.

_ and _, "No Guarantees, No Trade: How Banks Affect Export Patterns," Staff Report 659, Federal Reserve Bank of New York 2013. 
Paravisini, Daniel, Veronica Rappoport, Philipp Schnabl, and Daniel Wolfenzon, "Dissecting the Effect of Credit Supply on Trade: Evidence from Matched Credit-Export Data," Review of Economic Studies, forthcoming.

Petersen, Mitchell A and Raghuram G Rajan, "Trade Credit: Theories and Evidence," Review of Financial Studies, 1997, 10 (3), 661-91.

Prete, Silvia Del and Stefano Federico, "Trade and finance: is there more than just trade finance? Evidence from matched bank-firm data," 2012. mimeo.

Schmidt-Eisenlohr, Tim, "Towards a theory of trade finance," Journal of International Economics, 2013, 91 (1), 96 - 112.

Turkcan, Kemal and Veysel Avsar, "Investigating the Role of Contract Enforcement and Financial Costs on the Payment Choice: Industry-Level Evidence from Turkey," 2014. mimeo, Akdeniz University and Antalya International University.

Wilner, Benjamin S., "The Exploitation of Relationships in Financial Distress: The Case of Trade Credit," Journal of Finance, February 2000, 55 (1), 153-178.

Working Group on Trade, Debt and Finance, "Improving the availability of trade finance in developing countries: an assessment of remaining gaps," Note by the Secretariat, World Trade Organization 2014. 


\section{A Proofs}

Expected profits of good exporters are given by: ${ }^{44}$

$$
\begin{aligned}
\mathrm{E}\left[\Pi^{C I A}\right] & =\frac{\eta+(1-\eta) \lambda}{1+r^{*}} R-K, \\
\mathrm{E}\left[\Pi^{O A}\right] & =\frac{\eta^{*}+\left(1-\eta^{*}\right) \lambda^{*}}{1+r} R-K, \\
\mathrm{E}\left[\Pi_{E}^{D C}\right] & =\frac{\Lambda\left(\phi^{D C}\right)}{1+r} R-F^{D C}-K, \\
\mathrm{E}\left[\Pi^{L C}\right] & =\frac{1-(m / R)\left(1+r^{*}\right)}{(1+r)\left[1+\left(1-\Lambda\left(\phi^{L C}\right)\right)\right]} R-K,
\end{aligned}
$$

with $\Lambda(\phi)=\eta^{*}(1+\phi)+\left(1-\eta^{*}(1+\phi)\right) \lambda^{*}$.

Proof of proposition 1 Proof. It is easy to see that $\frac{\partial \mathrm{E}\left[\Pi^{C I A}\right]}{\partial \lambda^{*}}=0$ and that $\frac{\partial \mathrm{E}\left[\Pi^{L C}\right]}{\partial \lambda^{*}}>0$, $\frac{\partial \mathrm{E}\left[\Pi^{O A}\right]}{\partial \lambda^{*}}>0$, and $\frac{\partial \mathrm{E}\left[\Pi^{D C}\right]}{\partial \lambda^{*}}>0$. It therefore remains to be shown that $\frac{\partial \mathrm{E}\left[\Pi^{O A}\right]}{\partial \lambda^{*}}>\frac{\partial \mathrm{E}\left[\Pi^{D C}\right]}{\partial \lambda^{*}}$ and that $\frac{\partial \mathrm{E}\left[\Pi^{D C}\right]}{\partial \lambda^{*}}>\frac{\partial \mathrm{E}\left[\Pi^{L C}\right]}{\partial \lambda^{*}}$.

Begin by taking the difference between expected profits under open account and documentary collection:

$$
\mathrm{E}\left[\Pi^{O A}-\Pi^{D C}\right]=\frac{\eta^{*}+\left(1-\eta^{*}\right) \lambda^{*}}{1+r} R-\frac{\Lambda\left(\phi^{D C}\right)}{1+r} R-F^{D C}
$$

Taking the derivative with respect to $\lambda^{*}$ gives:

$$
\frac{\partial \mathrm{E}\left[\Pi^{O A}-\Pi^{D C}\right]}{\partial \lambda^{*}}=\frac{\eta^{*} \phi^{D C}}{1+r} R>0
$$

Next, take the difference between the expected profits from documentary collection and LC:

$$
\mathrm{E}\left[\Pi^{D C}-\Pi^{L C}\right]=\frac{\Lambda\left(\phi^{D C}\right)}{1+r} R-F^{D C}-\frac{1-(m / R)\left(1+r^{*}\right)}{(1+r)\left[1+\left(1-\Lambda\left(\phi^{L C}\right)\right)\right]} R .
$$

Taking the derivative with respect to $\lambda^{*}$ delivers:

$$
\frac{\partial\left(\mathrm{E}\left[\Pi^{D C}-\Pi^{L C}\right]\right)}{\partial \lambda^{*}}=\frac{1-\eta^{*}\left(1+\phi^{D C}\right)}{1+r} R-\frac{1-\eta^{*}\left(1+\phi^{L C}\right)}{1+r} R \frac{\left(1-(m / R)\left(1+r^{*}\right)\right)}{\left[1+\left(1-\Lambda\left(\phi^{L C}\right)\right)\right]^{2}}
$$

\footnotetext{
${ }^{44}$ These are sufficient because under pooling the equilibrium contract only depends on the optimal choice of good exporters. Bad exporters imitate whichever contract is optimally chosen by good firms.
} 
It is easy to see that this term is positive since $\phi^{L C}>\phi^{D C}$ and $\frac{\left(1-(m / R)\left(1+r^{*}\right)\right)}{\left[1+\left(1-\Lambda\left(\phi^{L C}\right)\right)\right]^{2}}<1$.

Proof of proposition 2 Proof. Expected profits over revenues are:

$$
\begin{aligned}
\mathrm{E}\left[\Pi^{C I A}\right] / R & =\frac{\eta+(1-\eta) \lambda}{1+r^{*}}-\gamma, \\
\mathrm{E}\left[\Pi^{O A}\right] / R & =\frac{\eta^{*}+\left(1-\eta^{*}\right) \lambda^{*}}{1+r}-\gamma, \\
\mathrm{E}\left[\Pi_{E}^{D C}\right] / R & =\frac{\Lambda\left(\phi^{D C}\right)}{1+r}-F^{D C} / R-\gamma, \\
\mathrm{E}\left[\Pi^{L C}\right] / R & =\frac{1-(m / R)\left(1+r^{*}\right)}{(1+r)\left[1+\left(1-\Lambda\left(\phi^{L C}\right)\right)\right]}-\gamma .
\end{aligned}
$$

Now, take the limit of these expressions when $R \rightarrow \infty$ for DC and LC:

$$
\begin{aligned}
\lim _{R \rightarrow \infty} \mathrm{E}\left[\Pi_{E}^{D C}\right] / R & =\frac{\Lambda\left(\phi^{D C}\right)}{1+r}-\gamma \\
\lim _{R \rightarrow \infty} \mathrm{E}\left[\Pi^{L C}\right] / R & =\frac{1}{(1+r)\left[1+\left(1-\Lambda\left(\phi^{L C}\right)\right)\right]}-\gamma
\end{aligned}
$$

Expressions for CIA and OA do not change with $R$. Note that we can either be in case $1(C \in$ $\{O A, D C, L C\})$ or case $2(C \in\{C I A, D C, L C\})$. For given parameters $\eta, \eta^{*}, \lambda, \lambda^{*}, r, r^{*}$, either CIA dominates over OA or vice versa, independent of the transaction size $R$.

Start with case 1, where, for some $R$, OA, DC or LC are used. Step 1: for $R$ sufficiently large, DC dominates OA. This directly follows from comparing equations (20) and (21). Step 2: for $R$ sufficiently large, LC dominates DC. For this, we need to compare equations (21) and (22). The following holds:

$$
\lim _{R \rightarrow \infty}\left(\mathrm{E}\left[\Pi^{L C}\right] / R-\mathrm{E}\left[\Pi_{E}^{D C}\right] / R\right)>0 \Leftrightarrow \Lambda\left(\phi^{D C}\right)\left(2-\Lambda\left(\phi^{L C}\right)\right)<1
$$

This can be rewritten as:

$$
\lim _{R \rightarrow \infty}\left(\mathrm{E}\left[\Pi^{L C}\right] / R-\mathrm{E}\left[\Pi_{E}^{D C}\right] / R\right)>0 \Leftrightarrow \Lambda\left(\phi^{D C}\right)\left(1-\Lambda\left(\phi^{L C}\right)\right)<1-\Lambda\left(\phi^{D C}\right) .
$$

This always holds because $1-\Lambda\left(\phi^{L C}\right)<1-\Lambda\left(\phi^{D C}\right)$ and $\Lambda\left(\phi^{D C}\right)<1$. Step 3: for $R$ sufficiently small, OA dominates DC and LC. This is easy to see: for $R \rightarrow 0, \mathrm{E}\left[\Pi_{E}^{D C}\right] / R$ and $\mathrm{E}\left[\Pi_{E}^{L C}\right] / R$ go to $-\infty$. We have shown that for very small values of $R$, open account 
dominates the two alternatives and for very large values of $R$, letter of credit is the best contract type. If $\mathrm{DC}$ is used for some $R$, this has to be the case for intermediate values of $R$.

The proof of case 2 is analogous. DC and LC become relatively more profitable the higher $R$. Hence, for very low values of $R$, cash-in-advance is chosen. For very high values of $R$, LC dominates, and at intermediate values, a DC is chosen.

\section{B Derivation of the Model}

In the following, we derive the optimal contract choice between cash-in-advance, open account, documentary collection and letter of credit. The assumptions on cash-in-advance and open account are as in Schmidt-Eisenlohr (2013). $\delta$, the parameter that captures enforcement costs in the original model, is set to zero. For more details, including an extensive discussion of the underlying assumptions, see Schmidt-Eisenlohr (2013). Documentary collections were not part of the original model and are studied here for the first time.

\section{B.1 Cash-in-advance}

There are two possible cases: a pooling case and a separating case. In the following, we first derive the optimal decision under pooling. We then study the separating case and derive the condition that assures pooling.

Pooling case Under pooling, the exporter maximizes her expected profits, respecting the participation constraint of the importer. Expected profits between good and bad exporters 
differ because bad exporters are only forced to produce with probability $\lambda$ :

$$
\begin{aligned}
\text { Good type: } \max _{C} \mathrm{E}\left[\Pi_{E, g}^{C I A, p}\right]= & C^{C I A, p}-K, \\
\text { Bad type: } \max _{C} \mathrm{E}\left[\Pi_{E, b}^{C I A, p}\right]= & C^{C I A, p}-\lambda K, \\
\text { s.t. } & \\
\mathrm{E}\left[\Pi_{I}^{C I A, p}\right]= & \frac{\eta+(1-\eta) \lambda}{1+r^{*}} R-C^{C I A, p} \geq 0 \\
& \text { (participation constraint importer) } \\
\mathrm{E}\left[\Pi_{E, g}^{C I A, p}\right]= & C^{C I A, p}-K \geq 0 \\
& \text { (participation constraint good exporter). }
\end{aligned}
$$

The optimal payment $C^{C I A, p}$ and optimal expected profits of a good and bad exporter, respectively, are:

$$
\begin{array}{r}
C^{C I A, p}=\frac{\eta+(1-\eta) \lambda}{1+r^{*}} R, \\
\text { Good type: } \mathrm{E}\left[\Pi_{E, g}^{C I A, p}\right]=\frac{\eta+(1-\eta) \lambda}{1+r^{*}} R-K, \\
\text { Bad type: } \mathrm{E}\left[\Pi_{E, b}^{C I A, p}\right]=\frac{\eta+(1-\eta) \lambda}{1+r^{*}} R-\lambda K .
\end{array}
$$

Separating First, note that if a good exporter chooses cash-in-advance, a bad exporter always chooses it as well and imitates the good type. This is strictly preferable to revealing her type as a higher pre-payment is received at no additional cost. If, however, good firms do not choose cash-in-advance, a bad firm might want to deviate and choose this contract. This case is considered in the following.

Suppose a good exporter does not choose cash-in-advance. Given the ability to default on the contract, a bad firm might still consider it optimal to offer a cash-in-advance contract, even though this implies revelation of her type. In this case, the importer understands that she deals with a bad firm and adjusts her expected revenue downwards. Her participation constraint becomes:

$$
\mathrm{E}\left[\Pi_{I}^{C I A, s}\right]=\frac{\lambda}{1+r^{*}} R-C^{C I A, s} \geq 0
$$


The pre-payment that makes the participation constraint of the importer bind is:

$$
C^{C I A, s}=\frac{\lambda}{1+r^{*}} R
$$

The expected profit of a bad exporter in the separating case with CIA is thus:

$$
\mathrm{E}\left[\Pi_{E, b}^{C I A, s}\right]=\frac{\lambda}{1+r^{*}} R-\lambda K
$$

A sufficient condition for the bad exporter not to choose cash-in-advance is that her expected profits in the separating case are less than the expected profits of a good firm in the pooling case. That is if:

$$
\mathrm{E}\left[\Pi_{E, g}^{C I A, p}\right]>\mathrm{E}\left[\Pi_{E, b}^{C I A, s}\right]
$$

Substituting the expected profits into the inequality above and rearranging delivers the condition from the main text:

$$
\frac{R}{K}>\frac{1+r^{*}}{\eta}
$$

\section{B.2 Open account}

Now, the exporter can choose between a pooling and a separating strategy. Pooling refers to the case where good and bad importers accept the proposed contract. In the separating case, only bad importers agree to buy the goods at the offered price. In the following, both cases are analyzed and then the pooling condition is derived.

\section{Pooling case}

$$
\begin{aligned}
\max _{C} \mathrm{E}\left[\Pi_{E}^{O A}\right] & =\frac{\eta^{*}+\left(1-\eta^{*}\right) \lambda^{*}}{1+r} C^{O A}-K, \\
\text { s.t. } & \\
\mathrm{E}\left[\Pi_{I, g}^{O A}\right] & =R-C^{O A} \geq 0
\end{aligned}
$$

(participation constraint good importer). 
It is optimal for the exporter to choose $C^{O A}$ such that the participation constraint of the good importer binds. This implies:

$$
\begin{aligned}
C^{O A} & =R \\
\mathrm{E}\left[\Pi_{E}^{O A}\right] & =\frac{\eta^{*}+\left(1-\eta^{*}\right) \lambda^{*}}{1+r} R-K .
\end{aligned}
$$

Separating The separating case implies the following participation constraint for a bad importer:

$$
\mathrm{E}\left[\Pi_{I, b}^{O A, s}\right]=\frac{R-\lambda^{*} C^{O A, s}}{1+r^{*}} \geq 0
$$

A binding participation constraint of a bad importer implies:

$$
C^{O A, s}=\frac{R}{\lambda^{*}}
$$

The prepayment $C^{O A}$ exactly offsets the risk of non-payment by the importer. In expectation, the importer thus pays $R$ to the exporter. Expected profits of the exporter are, however, reduced as good importers reject the contract and only bad importers (share $1-\eta^{*}$ ) accept it. Thus expected profits are:

$$
\mathrm{E}\left[\Pi_{E}^{O A, s}\right]=\left(1-\eta^{*}\right)\left(\frac{1}{1+r} R-K\right)
$$

Comparing profits, an exporter strictly prefers a pooling contract if:

$$
\frac{R}{K}>\frac{\eta^{*}(1+r)}{\eta^{*}-\left(1-\eta^{*}\right)\left(1-\lambda^{*}\right)}
$$

\section{B.3 Documentary collection}

A documentary collection reduces but does not eliminate the risk that the importer does not pay. To capture this aspect in the model, we assume that with a documentary collection, the

share of firms that try to cheat decreases by a factor $\phi^{D C} \in\left(0, \frac{1-\eta^{*}}{\eta^{*}}\right)$. The probability of payment therefore increases to $\eta^{*}\left(1+\phi^{D C}\right)+\left(1-\eta^{*}\left(1+\phi^{D C}\right)\right) \lambda^{*}$. A documentary collection, however, comes at a cost $F^{D C}$. Similar to open account, we have to distinguish between a 
pooling and a separating case.

Pooling case The pooling case in the documentary collection is very similar to open account. The only difference is a higher probability of payment and the additional fixed cost:

$$
\begin{aligned}
C^{D C} & =R \\
\mathrm{E}\left[\Pi_{E}^{D C}\right] & =\frac{\Lambda\left(\phi^{D C}\right)}{1+r} R-F^{D C}-K,
\end{aligned}
$$

with $\Lambda(\phi)=\eta^{*}(1+\phi)+\left(1-\eta^{*}(1+\phi)\right) \lambda^{*}$.

Separating case The separating case does only change compared to open account in that fewer firms are trying to deviate.

$$
\mathrm{E}\left[\Pi_{I, b}^{D C, s}\right]=\frac{R-\lambda^{*} C^{D C, s}}{1+r^{*}} \geq 0
$$

A binding participation constraint of a bad importer implies:

$$
C^{D C, s}=\frac{R}{\lambda^{*}}
$$

As before, the prepayment $C^{D C}$ exactly offsets the risk of non-payment by the importer. In expectation the importer thus pays $R$ to the exporter. Expected profits of the exporter are reduced because good importers and bad importers that do not cheat under a documentary collection reject the contract, and only the remaining bad importers ( share $1-\eta^{*}\left(1+\phi^{D C}\right)$ ) accept it. Expected profits are:

$$
\mathrm{E}\left[\Pi_{E}^{D C, s}\right]=\left(1-\eta^{*}\left(1+\phi^{D C}\right)\right)\left(\frac{1}{1+r} R-F^{D C}-K\right)
$$

Comparing profits, an exporter strictly prefers a pooling contract if:

$$
\frac{R}{K+F^{D C}}>\frac{\eta^{*}\left(1+\phi^{D C}\right)(1+r)}{\eta^{*}\left(1+\phi^{D C}\right)-\left(1-\eta^{*}\left(1+\phi^{D C}\right)\right)\left(1-\lambda^{*}\right)} .
$$




\section{B.4 Letter of credit}

With a letter of credit, the payment is guaranteed by the issuing bank. The exporter therefore gets paid with certainty if she delivers the goods. Again, we need to distinguish between a pooling and a separating case.

Pooling case The maximization problem is:

$$
\begin{aligned}
& \max _{C} \mathrm{E}\left[\Pi_{E}^{L C}\right]=\frac{C^{L C}}{1+r}-K, \\
& \text { s.t. } \mathrm{E}\left[\Pi_{I, g}^{L C}\right]=\frac{R-C^{L C}}{1+r^{*}}-F^{L C} \geq 0 \quad \text { (participation constraint importer). }
\end{aligned}
$$

In the optimum, the participation constraint of the good importer binds. The optimal payment and expected profits are:

$$
C^{L C}=R-F^{L C}\left(1+r^{*}\right)
$$

Plugging in the the expression for $F^{L C}$ from the main text in equation (5) delivers:

$$
C^{L C}=R-m\left(1+r^{*}\right)+\left(1-\Lambda\left(\phi^{L C}\right)\right) C^{L C}=\frac{1-(m / R)\left(1+r^{*}\right)}{\left.2-\Lambda\left(\phi^{L C}\right)\right)} R
$$

This implies the following exporter profits:

$$
\Pi^{L C}=\frac{1-(m / R)\left(1+r^{*}\right)}{\left.(1+r)\left[2-\Lambda\left(\phi^{L C}\right)\right)\right]} R-K
$$

Separating case The exporter chooses $C^{L C, s}$ that makes the participation constraint of a bad importer bind:

$$
\mathrm{E}\left[\Pi_{I, b}^{L C, s}\right]=\frac{R-\lambda^{*} C^{L C, s}}{1+r^{*}}-F^{L C} \geq 0
$$

Plugging in $F^{L C}$, we get:

$$
C^{L C, s}=\frac{R-\left(1+r^{*}\right) m}{\lambda^{*}+1-\Lambda\left(\phi^{L C}\right)} .
$$


The prepayment $C^{L C}$ depends on the probability that the importer does not pay and the letter of credit fee $m$. The exporter's expected profits are reduced as good importers and bad importers that do not cheat under a letter of credit reject the contract and only the remaining bad importers (share $\left.1-\eta^{*}\left(1+\phi^{L C}\right)\right)$ accept it. Expected profits are:

$$
\mathrm{E}\left[\Pi_{E}^{L C, s}\right]=\left(1-\eta^{*}\left(1+\phi^{L C}\right)\right)\left(\frac{\left(1-(m / R)\left(1+r^{*}\right)\right)}{(1+r)\left[\lambda^{*}+\left(1-\Lambda\left(\phi^{L C}\right)\right)\right]} R-K\right) .
$$

Comparing profits, an exporter strictly prefers a pooling contract if:

$$
\frac{R}{K}>\frac{\left.\eta^{*}\left(1+\phi^{L C}\right)(1+r)\left(1+\kappa_{2}\right)\left(\lambda^{*}+\kappa_{2}\right)\right)}{\left(1-\kappa_{1}\right)\left[\left(\lambda^{*}+\kappa_{2}\right)-\left(1-\eta^{*}\left(1+\phi^{L C}\right)\right)\left(1+\kappa_{2}\right)\right]}
$$

with $\kappa_{1}=\frac{m}{R}\left(1+r^{*}\right)$ (fixed monitoring component of letter of credit fee) and $\kappa_{2}=1-\Lambda\left(\phi^{L C}\right.$ ) (risk component of letter of credit fee).

Discussion: pooling and separating cases: In the main text of the paper, we follow Schmidt-Eisenlohr (2013) and focus on the pooling cases for all contracts. This is reasonable for two reasons. First, the pooling case dominates for relatively weak conditions on the ratio $R / K$. As long as revenues over production costs are sufficiently large, it is optimal to offer contracts also acceptable by good type firms.

Second and more importantly, the pooling case is intuitively the economically relevant one. In the pooling case, the agreed payment is lower or equal than the final sales price, that is, $C \leq R$. Also, the price is not so high to generate adverse selection and leave only bad firms in the market. In the separating case, the exporter demands a payment that exceeds the final sales value of the goods $R$ because she knows with certainty that she is dealing with a bad counter-party. This generates adverse selection and only bad trading partners are left.

Except for a few extreme countries in which the rule of law is extremely weak and the fraction of good firms is very low, we should not expect to observe this pattern. Hence, we concentrate on the pooling cases and assume that the relevant conditions are satisfied. This is the case if there are sufficiently many good firms reflected in high $\eta, \eta^{*}$, and if the profit opportunities $R / K$ in international trade are sufficiently large. 


\section{Data Appendix}

\section{Data sources}

- FFIEC 009 data: Statistics Group, Federal Reserve Bank of New York.

- SWIFT MT400 and MT700 messages: SWIFT Institute.

- Trade data: Quarterly trade data is from the IMF's Directions of Trade Statistics; yearly data is obtained by summing over 4 quarters.

- Rule of law: World Government Indicators from the World Bank normalized as follows: $l a w_{\text {new }}=\frac{l a w_{\text {old }}-\min \left(l a w_{\text {old }}\right)}{\max \left(l a w_{\text {old }}\right)-\min \left(l a w_{o l d}\right)}$.

- Nominal GDP per capita: Annual numbers are from the World Bank's World Development Indicators.

- Investor protection index: Doing Business Indicators from the World Bank.

- Distance and other gravity variables: CEPII. For a description, see Mayer and Zignago (2005).

- Financial development: proxied by private credit by deposit money banks over GDP from Financial Structure Database provided by the World Bank. For a description, see Beck et al. (2009).

- Letter of credit requirements: Information on whether a country requires that importers use of letters of credit is from the IMF's Annual Report on Exchange Arrangements and Exchange Restrictions (ARERER).

\section{Offshore Centers (excluded)}

Netherlands Antilles, United Arab Emirates, Bahrain, Bahamas, Belize, Bermuda, Barbados, Cayman Islands, Cyprus, Grenada, Hong Kong, Oman, Ireland, Jordan, Lebanon, Macao, Monaco, Maldives, Malta, Mauritius, Seychelles, Taiwan, Vanuatu, Samoa

\section{FFIEC 009 Data}

U.S. banks and U.S. subsidiaries of foreign banks that have more than $\$ 30$ million in total foreign assets are required to file the Country Exposure Report (FFIEC 009). They have to 
include information on their claims (including commitments and guarantees) with maturities of up to one year against parties residing in foreign countries, that are "directly related to exports and imports and will be liquidated through the proceeds of international trade." The exact reporting instructions for the trade finance item in the FFIEC 009 Report are as follows:

"Report total extensions of credit with maturities one year and under [...] that: (1) are directly related to imports or exports and (2) will be liquidated through the proceeds of international trade. Provided these two conditions are met, such credit extensions may include customers' liability on acceptances outstanding, own acceptances discounted, acceptances of other banks purchased, pre-export financing where there is a firm export sales order, commercial LCs, as well as other loans and advances whenever such extensions directly relate to international trade. Include credit extensions for pre-export financing when there is a firm export sales order and the proceeds of the order will pay off indebtedness." Trade finance claims are reported by country at a quarterly frequency; and they are on a consolidated basis, that is, they include the exposures of banks' foreign affiliates. ${ }^{45}$

At first glance, it is not obvious which trade finance instruments are reflected in the reported claims nor how trade finance claims relate to U.S. exports and imports. To clarify what the data capture, we study the reporting instructions, analyze correlations between banks' trade finance claims and trade, and compare the FFIEC 009 data with the SWIFT data. In the following, we summarize the results of this analysis, which shows that (i) banks' trade finance claims largely reflect trade finance in support of U.S. exports; (ii) the main instrument in the data are letters of credit, and the data do not include documentary collections; and (iii) the data capture at least 85 percent of U.S. banks' trade finance claims.

Trade finance claims are related to U.S. exports The purpose of the FFIEC 009 report is to evaluate banks' exposures to foreign countries. If a bank could suffer a loss

\footnotetext{
${ }^{45}$ For data through 2005, trade finance claims are reported on an immediate borrower basis; that is, a claim is attributed to the country in which the contracting counter-party resides. Beginning with the data for 2006, claims are reported on an ultimate risk basis; that is, a claim is attributed to the country of the ultimate guarantor of the claim. See http://www.ffiec.gov/ for more details. This reporting change does not appear to affect the value of banks' trade finance claims in a systematic way; consequently, we use the entire time series without explicitly accounting for the change. Statisticians at the Federal Reserve Bank of New York, who are familiar with the reporting instructions, confirm that risk transfers, for which values on an immediate borrower basis diverge from those on an ultimate risk basis, are less relevant for trade finance products.
} 
because a foreign party defaults on its obligation to pay, the bank has to report the potential loss as a claim on the country in which the foreign party resides. U.S. banks do not have to indicate their claims on U.S. parties. Theoretically, banks' trade finance claims could be related to U.S. import and export activity as well as to third-party trade, given that banks provide information on a consolidated basis and include loans and guarantees extended by their foreign affiliates. Table 8 displays the trade finance instruments that could be included in the data according to the reporting instructions. However, a close investigation of the data indicates that only instruments in support of U.S. exports matter.

Columns (1) to (3) of table 9 show the results from OLS regressions, in which the log of banks' total trade finance claims in quarter $t$ in country $c$ is regressed on the log of imports from country $c$, the $\log$ of exports to country $c$ and total non-U.S. imports and exports of country $c$ in quarter $t$. Columns (2) and (3) include time fixed effects. In column (3), country fixed effects are added. The estimated coefficients suggest that banks' trade finance claims are primarily driven by U.S. exports. Column (1) implies that a 10 percent increase in U.S. exports to a destination raises U.S. banks' trade finance claims by 8.6 percent. Only the coefficient on exports is significant at standard significance levels, and the point estimates on U.S. imports as well as on non-U.S. imports and exports are small or negative.

Trade finance claims reflect letters of credit If a U.S. bank confirms or issues an LC, it pays the exporter before obtaining the payment from the importer. Thus the bank runs the risk that the importer defaults. In a documentary collection, the bank forwards the collection but does not advance or guarantee the payment, so documentary collections do not expose banks to default risk.

The SWIFT data allow us to directly check the extent to which the claims data capture letters of credit and documentary collections. Columns (4)-(9) of table 9 show correlations between banks' trade finance claims and the SWIFT data. In columns (4)-(6), log claims by country are regressed on log exports, on the log number of LC messages and on the log number of DC messages. Columns (7)-(9) use message values instead of counts as regressors. The results indicate a tight link between trade finance claims and LC messages, regardless of which fixed effects are included in the regression. Documentary collections are not correlated with banks' trade finance claims, which confirms our interpretation of the FFIEC 009 
reporting instructions. The fact that all coefficients are insignificant in column (9) is due to the limited time variation in the sample (2010 q4 to 2012 q2) and the inclusion of country fixed effects. ${ }^{46}$

We can also compare the total value of LC messages and trade finance claims. In the fourth quarter of 2010, the total value of LC messages corresponded to roughly 67 percent of banks' aggregate trade finance claims. ${ }^{47}$ The discrepancy between SWIFT LC (MT700) values and FFIEC 009 values increases after 2010, with the value of LC messages falling to around 50 percent of bank claims. This is due to the fact that U.S. banks expanded their trade finance business in Asia through foreign affiliates after the global financial crisis. More trade finance in support of third-party trade may therefore be included in the claims data in the most recent years. The majority of claims are, however, related to LCs for U.S. exports, especially before 2011 .

In addition to the above analysis, section 6 shows that the FFIEC 009 data and the SWIFT data largely follow the same patterns. The key regression results on letters of credit expected from the theory hold for both LC messages from SWIFT and the claims data. This reinforces our conclusion that banks' trade finance claims capture mostly letters of credit in support of U.S. exports.

Data captures at least 85 percent of total trade finance claims The only institutions required to file the Country Exposure Report are those U.S. banks and U.S. subsidiaries of foreign banks with more than $\$ 30$ million in foreign assets. However, the reporting threshold is not a major concern. First, the letter of credit business is known to be highly concentrated. In a data set that captures the universe of Italian banks, Del Prete and Federico (2012) find that only 10 large banks provide trade guarantees to Italian firms. The high concentration is also reflected in the claims data. In the first quarter of 2012, we observe 18 banks with posi-

\footnotetext{
${ }^{46}$ As discussed above, LC transactions for U.S. imports cannot be captured by the FFIEC 009 data, as they would constitute claims against U.S. residents. We confirmed this by including the number of U.S. import LCs from the SWIFT data as an additional independent variable in the regressions in table 9, which delivered insignificant coefficients.

${ }^{47}$ The actual amount sent through SWIFT is marginally higher than the observed amounts because, to reduce the chance that the data might be used to identify individual institutions, the data released by the SWIFT Institute do not show monthly values that are composed of less than four transactions. Also, although the FFIEC 009 and the SWIFT data are roughly comparable, we should not expect a perfect match between the two data sets because, as discussed in more detail below, the former capture end-of-quarter stocks whereas the latter measure LC flows.
} 
tive trade finance claims, whereas 51 banks report no claims. Second, and more importantly, there is a strong positive relationship between the probability of having non-zero trade finance claims and bank size. This suggests that the trade finance claims of banks below the reporting threshold are small. The following back-of-the-envelope calculation supports this conclusion.

Assume that all commercial banks in the United States below the reporting threshold (around 6,000 banks) had $\$ 30$ million of foreign assets (the reporting threshold), and suppose that 9.4 percent of the foreign assets were trade finance claims (the mean exposure of banks in the data in 2012 q1). Total trade finance claims would then be about $\$ 84$ billion in 2012 q1. Even under these extremely conservative assumptions, the FFIEC 009 data would still capture about 85 percent of U.S. banks' trade finance claims.

Mapping between exports and bank claims While the number of SWIFT messages and exports are flow variables, trade finance claims are stocks taken at the end of a quarter. For the period that the bank is exposed to a potential default by the importer, that is, from the extension of the trade guarantee until it receives the payment from the importer, the related claims appear on its books. According to ICC (2013), which uses data from international banks participating in the ICC's Trade Register, the average maturity of a confirmed LC is 70 days, while the average maturity of an importer LC is about 80 days. It thus makes sense to relate quarterly trade finance claims to quarterly exports. 


\section{E Tables}

Table 1: Tradeoffs between different payment forms

\begin{tabular}{l|cc|cc|cc|cc}
\hline \hline & \multicolumn{3}{|c}{ OA } & \multicolumn{2}{c}{ CIA } & DC & LC \\
& risk & financial costs & risk & financial costs & risk & financial costs & risk & financial costs \\
\hline exporter & ++ & + & - & - & + & ++ & - & + \\
importer & - & - & ++ & + & - & - & - & + \\
\hline \hline
\end{tabular}

Note: The table illustrates the differences between the four payment contracts in terms of risk allocation and financing costs. The notation has the following interpretation. Risk: ++ all risk, + some risk, - no risk. Financial costs: ++ interest expenses and fees, + interest expenses or fees, - zero costs. 
Table 2: Letters of credit, documentary collections and rule of law

\begin{tabular}{|c|c|c|c|c|c|}
\hline & $\begin{array}{c}(1) \\
\log \left(\# \mathrm{LC}_{\mathrm{ct}}\right)\end{array}$ & $\begin{array}{c}(2) \\
\log \left(\# \mathrm{DC}_{\mathrm{ct}}\right)\end{array}$ & $\begin{array}{c}(3) \\
\log \left(\# \mathrm{SWIFT}_{\mathrm{mct}}\right)\end{array}$ & $\begin{array}{c}(4) \\
\log \left(\# \mathrm{LC}_{\mathrm{ct}}\right)\end{array}$ & $\begin{array}{c}(5) \\
\log \left(\# \mathrm{DC}_{\mathrm{ct}}\right)\end{array}$ \\
\hline $\log \left(\operatorname{exports}_{\mathrm{ct}}\right)$ & $\begin{array}{l}0.902^{* * *} \\
(0.0595)\end{array}$ & $\begin{array}{c}0.898^{* * *} \\
(0.0570)\end{array}$ & $\begin{array}{c}0.881^{* * *} \\
(0.0419)\end{array}$ & $\begin{array}{c}0.875^{* * *} \\
(0.0603)\end{array}$ & $\begin{array}{l}0.890^{* * *} \\
(0.0625)\end{array}$ \\
\hline $\log \left(\right.$ distance $\left._{c}\right)$ & $\begin{array}{c}0.632^{* * *} \\
(0.176)\end{array}$ & $\begin{array}{c}1.301^{* * *} \\
(0.378)\end{array}$ & $\begin{array}{c}0.890^{* * *} \\
(0.173)\end{array}$ & $\begin{array}{l}0.590^{* *} \\
(0.227)\end{array}$ & $\begin{array}{l}1.225^{*} \\
(0.637)\end{array}$ \\
\hline rule of law $w_{c t}$ & $\begin{array}{c}7.986^{* * *} \\
(2.577)\end{array}$ & $\begin{array}{c}12.63^{* * *} \\
(3.629)\end{array}$ & $\begin{array}{c}5.789^{* * *} \\
(1.660)\end{array}$ & $\begin{array}{c}0.634 \\
(2.828)\end{array}$ & $\begin{array}{c}11.57^{* *} \\
(5.389)\end{array}$ \\
\hline rule of $\operatorname{law}^{2}$ ct & $\begin{array}{c}-7.805^{* * *} \\
(2.025)\end{array}$ & $\begin{array}{c}-6.069^{* *} \\
(2.685)\end{array}$ & $\begin{array}{c}-5.934^{* * *} \\
(1.266)\end{array}$ & $\begin{array}{l}-2.316 \\
(2.278)\end{array}$ & $\begin{array}{l}-4.984 \\
(4.137)\end{array}$ \\
\hline DC dummymct & & & $\begin{array}{c}-3.476^{* * *} \\
(0.432)\end{array}$ & & \\
\hline DC dummy mct $*$ rule of law ct & & & $\begin{array}{c}5.081^{* * *} \\
(0.657)\end{array}$ & & \\
\hline long dist. dummy ${ }_{c}$ & & & & $\begin{array}{c}-3.160^{* *} \\
(1.227)\end{array}$ & $\begin{array}{l}-0.170 \\
(2.393)\end{array}$ \\
\hline l.d. dummy ${ }_{c} *$ rule of law ${ }_{c t}$ & & & & $\begin{array}{l}10.72^{* *} \\
(4.150)\end{array}$ & $\begin{array}{c}2.321 \\
(7.314)\end{array}$ \\
\hline l.d. dummy ${ }_{c} *$ rule of law $^{2} \mathrm{ct}$ & & & & $\begin{array}{c}-7.338^{* *} \\
(3.402)\end{array}$ & $\begin{array}{l}-2.686 \\
(5.538)\end{array}$ \\
\hline $\log \left(\right.$ GDP per cap $\left.{ }_{c t}\right)$ & $\begin{array}{l}-1.412^{*} \\
(0.794)\end{array}$ & $\begin{array}{l}1.052 \\
(0.955)\end{array}$ & $\begin{array}{l}-0.523 \\
(0.535)\end{array}$ & $\begin{array}{l}-1.312 \\
(0.823)\end{array}$ & $\begin{array}{c}1.384 \\
(1.008)\end{array}$ \\
\hline $\log (\text { GDP per cap } \text { ct })^{2}$ & $\begin{array}{c}0.0643 \\
(0.0491)\end{array}$ & $\begin{array}{l}-0.0722 \\
(0.0582)\end{array}$ & $\begin{array}{c}0.0149 \\
(0.0331)\end{array}$ & $\begin{array}{c}0.0578 \\
(0.0501)\end{array}$ & $\begin{array}{l}-0.0906 \\
(0.0619)\end{array}$ \\
\hline $\log (\text { fin. development })_{\mathrm{ct}}$ & $\begin{array}{c}0.597^{* * *} \\
(0.177)\end{array}$ & $\begin{array}{l}0.0629 \\
(0.218)\end{array}$ & $\begin{array}{c}0.429^{* * *} \\
(0.149)\end{array}$ & $\begin{array}{c}0.591^{* * *} \\
(0.175)\end{array}$ & $\begin{array}{l}0.0646 \\
(0.215)\end{array}$ \\
\hline $\mathrm{LC}_{\text {requirement }}{ }_{\mathrm{ct}}$ & $\begin{array}{c}0.372 \\
(0.251)\end{array}$ & $\begin{array}{l}0.0616 \\
(0.338)\end{array}$ & $\begin{array}{c}0.251 \\
(0.211)\end{array}$ & $\begin{array}{c}0.365 \\
(0.253)\end{array}$ & $\begin{array}{c}-0.00818 \\
(0.335)\end{array}$ \\
\hline Time FE & Yes & Yes & Yes & Yes & Yes \\
\hline Observations & 1,159 & 838 & 2,015 & 1,159 & 838 \\
\hline R-squared & 0.689 & 0.726 & 0.693 & 0.703 & 0.728 \\
\hline
\end{tabular}

Note: This table analyzes the relationship between the use of letters of credit and documentary collections and a destination's rule of law. $\log \left(\# \mathrm{LC}_{c t}\right)$ and $\log \left(\# \mathrm{DC}_{c t}\right)$ are the $\operatorname{logs}$ of the number of MT700 and MT400 messages received by U.S. banks, respectively. $\log \left(\right.$ \# SWIFT $_{m c t}$ ) is the log of the number of SWIFT messages of type $m \in\{L C, D C\}$. DC dummy ${ }_{m c t}$ takes a value of 1 if the message refers to a $\mathrm{DC}$ and a value of 0 if the message is related to an $\mathrm{LC}$. The variable long dist. dummy ${ }_{c}$ take a value of 1 if the destination country has an above-median distance from the U.S. and zero otherwise. Standard errors are clustered at the country level and are in parentheses. ${ }^{*}, * *$ and ${ }^{* * *}$ denote significance at the $10 \%, 5 \%$ and $1 \%$ level. 
Table 3: Share of letters of credit in bank intermediated trade

\begin{tabular}{|c|c|c|}
\hline & $\begin{array}{c}(1) \\
\mathrm{LC} \text { share }_{\mathrm{ct}}\end{array}$ & $\begin{array}{c}(2) \\
\mathrm{LC} \text { share }_{\mathrm{ct}}\end{array}$ \\
\hline rule of law ct $_{\text {. }}$ & $\begin{array}{c}-0.848^{* * *} \\
(0.0886)\end{array}$ & $\begin{array}{c}-0.607^{* * *} \\
(0.213)\end{array}$ \\
\hline $\log \left(\operatorname{exports}_{\mathrm{ct}}\right)$ & & $\begin{array}{r}-0.00186 \\
(0.0109)\end{array}$ \\
\hline $\log \left(\right.$ distance $\left._{c}\right)$ & & $\begin{array}{l}-0.0240 \\
(0.0475)\end{array}$ \\
\hline $\log ($ GDP per cap ct $)$ & & $\begin{array}{l}0.0203 \\
(0.139)\end{array}$ \\
\hline $\log (\text { fin. development })_{\mathrm{ct}}$ & & $\begin{array}{l}0.00323 \\
(0.0327)\end{array}$ \\
\hline $\mathrm{LC}$ requirement ${ }_{\mathrm{ct}}$ & & $\begin{array}{c}-0.0293 \\
(0.0447)\end{array}$ \\
\hline $\log \left(\mathrm{GDP} \text { per cap }{ }_{\mathrm{ct}}\right)^{2}$ & & $\begin{array}{l}-0.00396 \\
(0.00908)\end{array}$ \\
\hline Time FE & No & Yes \\
\hline Observations & 933 & 933 \\
\hline R-squared & 0.375 & 0.392 \\
\hline
\end{tabular}

Note: This table shows how the importance of letters of credit relative to documentary collections changes with a destination's rule of law. The dependent variable is the share of letter of credit messages (MT700) in total trade finance messages sent (MT700+MT400). Standard errors are clustered at the country level and are in parentheses. ${ }^{*}, * *$ and $* * *$ denote significance at the $10 \%, 5 \%$ and $1 \%$ level.

Table 4: Transaction size and choice of payment contract

\begin{tabular}{lcc}
\hline \hline & $(1)$ & $(2)$ \\
& all countries & large \\
& 0.9286 & 0.9762 \\
LC $>$ DC & $0.9280 r t s$ \\
LC $>$ TR & 0.9524 & 1.0000 \\
DC $>$ TR & 0.7857 & 0.9048 \\
\hline$N$ & 84 & 42 \\
\hline \hline
\end{tabular}

Note: This table reports the share of countries in which average transaction sizes are ordered as predicted by the theory. The first column reports the shares based on all 84 countries for which data on the numbers and values of letters of credit (LCs), documentary collections (DCs) and overall exports (TR) are available. The second column reports the statistics for those countries with above median exports. The first row reports which share of countries has an average LC value that is higher than the average DC value. Rows 2 and 3 compare LC and DC average values with overall exports, respectively. 
Table 5: Robustness I: region and country dummies

\begin{tabular}{|c|c|c|c|c|c|}
\hline & $\begin{array}{c}(1) \\
\log \left(\# \mathrm{LC}_{\mathrm{ct}}\right)\end{array}$ & $\begin{array}{c}(2) \\
\log \left(\# \mathrm{DC}_{\mathrm{ct}}\right)\end{array}$ & $\begin{array}{c}(3) \\
\log \left(\# \text { SWIFT }_{\text {mct }}\right)\end{array}$ & $\begin{array}{c}(4) \\
\log \left(\# \mathrm{LC}_{\mathrm{ct}}\right)\end{array}$ & $\begin{array}{c}(5) \\
\log \left(\# \mathrm{DC}_{\mathrm{ct}}\right)\end{array}$ \\
\hline $\log \left(\operatorname{exports}_{\mathrm{ct}}\right)$ & $\begin{array}{l}0.782^{* * *} \\
(0.0710)\end{array}$ & $\begin{array}{l}0.905^{* * *} \\
(0.0752)\end{array}$ & $\begin{array}{l}0.813^{* * *} \\
(0.0538)\end{array}$ & $\begin{array}{l}0.781^{* * *} \\
(0.0701)\end{array}$ & $\begin{array}{c}0.891^{* * *} \\
(0.0773)\end{array}$ \\
\hline $\log \left(\right.$ distance $\left._{c}\right)$ & $\begin{array}{c}1.434^{* * *} \\
(0.372)\end{array}$ & $\begin{array}{c}0.472 \\
(0.775)\end{array}$ & $\begin{array}{c}0.987^{* *} \\
(0.405)\end{array}$ & $\begin{array}{c}1.488^{* * *} \\
(0.449)\end{array}$ & $\begin{array}{c}0.233 \\
(0.833)\end{array}$ \\
\hline rule of lawct & $\begin{array}{l}5.561^{*} \\
(2.905)\end{array}$ & $\begin{array}{c}14.25^{* * *} \\
(3.992)\end{array}$ & $\begin{array}{c}5.215^{* * *} \\
(1.840)\end{array}$ & $\begin{array}{c}0.379 \\
(2.882)\end{array}$ & $\begin{array}{c}15.29 * * \\
(5.897)\end{array}$ \\
\hline rule of law ${ }^{2}$ ct & $\begin{array}{c}-5.403^{* *} \\
(2.161)\end{array}$ & $\begin{array}{c}-7.655^{* *} \\
(3.147)\end{array}$ & $\begin{array}{c}-5.323 * * * \\
(1.483)\end{array}$ & $\begin{array}{l}-1.437 \\
(2.227)\end{array}$ & $\begin{array}{c}-8.325^{*} \\
(4.582)\end{array}$ \\
\hline DC dummymct & & & $\begin{array}{c}-3.472^{* * *} \\
(0.426)\end{array}$ & & \\
\hline DC dummymct $*$ rule of law ${ }_{c t}$ & & & $\begin{array}{c}5.091^{* * *} \\
(0.654)\end{array}$ & & \\
\hline long dist. dummy ${ }_{c}$ & & & & $\begin{array}{c}-2.441^{*} \\
(1.274)\end{array}$ & $\begin{array}{c}1.194 \\
(2.293)\end{array}$ \\
\hline l.d. dummy $_{\mathrm{c}} *$ rule of law $\mathrm{w}_{\mathrm{ct}}$ & & & & $\begin{array}{l}8.298^{*} \\
(4.210)\end{array}$ & $\begin{array}{l}-2.030 \\
(7.597)\end{array}$ \\
\hline 1.d. dummy ${ }_{c} *$ rule of law $^{2}$ ct & & & & $\begin{array}{c}-6.190^{*} \\
(3.402)\end{array}$ & $\begin{array}{c}1.027 \\
(5.898)\end{array}$ \\
\hline India dummy ${ }_{c}$ & $\begin{array}{c}1.356^{* *} \\
(0.642)\end{array}$ & $\begin{array}{c}0.667 \\
(0.537)\end{array}$ & $\begin{array}{c}1.066^{* *} \\
(0.485)\end{array}$ & $\begin{array}{c}1.204^{*} \\
(0.668)\end{array}$ & $\begin{array}{c}0.731 \\
(0.561)\end{array}$ \\
\hline China dummy $_{c}$ & $\begin{array}{c}0.754 \\
(0.549)\end{array}$ & $\begin{array}{c}-0.611 \\
(0.438)\end{array}$ & $\begin{array}{c}0.108 \\
(0.397)\end{array}$ & $\begin{array}{c}0.734 \\
(0.595)\end{array}$ & $\begin{array}{l}-0.694 \\
(0.424)\end{array}$ \\
\hline South Korea dummyc & $\begin{array}{c}2.228^{* * *} \\
(0.354)\end{array}$ & $\begin{array}{c}-0.304 \\
(0.313)\end{array}$ & $\begin{array}{c}1.042^{* * *} \\
(0.273)\end{array}$ & $\begin{array}{c}2.113^{* * *} \\
(0.342)\end{array}$ & $\begin{array}{c}-0.255 \\
(0.329)\end{array}$ \\
\hline Asia dummy ${ }_{c}$ & $\begin{array}{c}0.109 \\
(0.452)\end{array}$ & $\begin{array}{c}0.160 \\
(0.493)\end{array}$ & $\begin{array}{c}0.120 \\
(0.368)\end{array}$ & $\begin{array}{c}0.108 \\
(0.453)\end{array}$ & $\begin{array}{c}0.149 \\
(0.485)\end{array}$ \\
\hline Europe dummy & $\begin{array}{l}0.0447 \\
(0.387)\end{array}$ & $\begin{array}{c}-0.194 \\
(0.458)\end{array}$ & $\begin{array}{c}-0.0535 \\
(0.334)\end{array}$ & $\begin{array}{c}0.0603 \\
(0.464)\end{array}$ & $\begin{array}{c}-0.0473 \\
(0.517)\end{array}$ \\
\hline North America dummy ${ }_{c}$ & $\begin{array}{l}1.408^{* *} \\
(0.569)\end{array}$ & $\begin{array}{c}-1.790^{*} \\
(0.918)\end{array}$ & $\begin{array}{l}0.102 \\
(0.516)\end{array}$ & $\begin{array}{c}1.337^{* *} \\
(0.564)\end{array}$ & $\begin{array}{r}-1.705^{*} \\
(0.894)\end{array}$ \\
\hline Oceania dummy $_{c}$ & $\begin{array}{c}-0.950^{* *} \\
(0.436)\end{array}$ & $\begin{array}{c}0.247 \\
(0.637)\end{array}$ & $\begin{array}{c}-0.287 \\
(0.403)\end{array}$ & $\begin{array}{c}-0.943^{* *} \\
(0.457)\end{array}$ & $\begin{array}{c}0.257 \\
(0.648)\end{array}$ \\
\hline South America dummy ${ }_{c}$ & $\begin{array}{c}1.618^{* * *} \\
(0.429)\end{array}$ & $\begin{array}{c}0.443 \\
(0.661)\end{array}$ & $\begin{array}{c}1.124^{* * *} \\
(0.391)\end{array}$ & $\begin{array}{c}1.438^{* * *} \\
(0.432)\end{array}$ & $\begin{array}{c}0.581 \\
(0.665)\end{array}$ \\
\hline Time FE & Yes & Yes & Yes & Yes & Yes \\
\hline Observations & 1,159 & 838 & 2,015 & 1,159 & 838 \\
\hline R-squared & 0.724 & 0.747 & 0.708 & 0.730 & 0.750 \\
\hline
\end{tabular}

Note: This table is similar to table 2, showing that the baseline results do not change when continent and several country dummies are added as control variables. $\log \left(\# \mathrm{LC}_{c t}\right)$ and $\log \left(\# \mathrm{DC}_{c t}\right)$ are the $\operatorname{logs}$ of the number of MT700 and MT400 messages received by U.S. banks, respectively. $\log \left(\# \mathrm{SWIFT}_{m c t}\right.$ ) is the $\log$ of

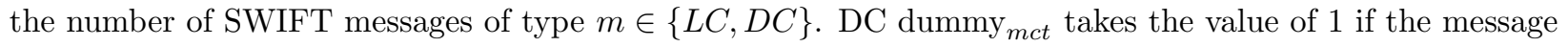
refers to a DC and a value of 0 if the message is related to an LC. The variable long dist. dummy ${ }_{c}$ is 1 if the destination country has an above-median distance from the U.S. and zero otherwise. All regressions control for $\log \left(\right.$ GDP per cap $\left.\mathrm{ct}_{\mathrm{ct}}\right), \log \left(\mathrm{GDP} \text { per } \mathrm{cap}_{\mathrm{ct}}\right)^{2}$ and $\log$ (fin. development). The dummy for Africa is omitted, serving as the base. Standard errors are clustered at the country level and are in parentheses. ${ }^{*}, * *$ and $* * *$ denote significance at the $10 \%, 5 \%$ and $1 \%$ level. 


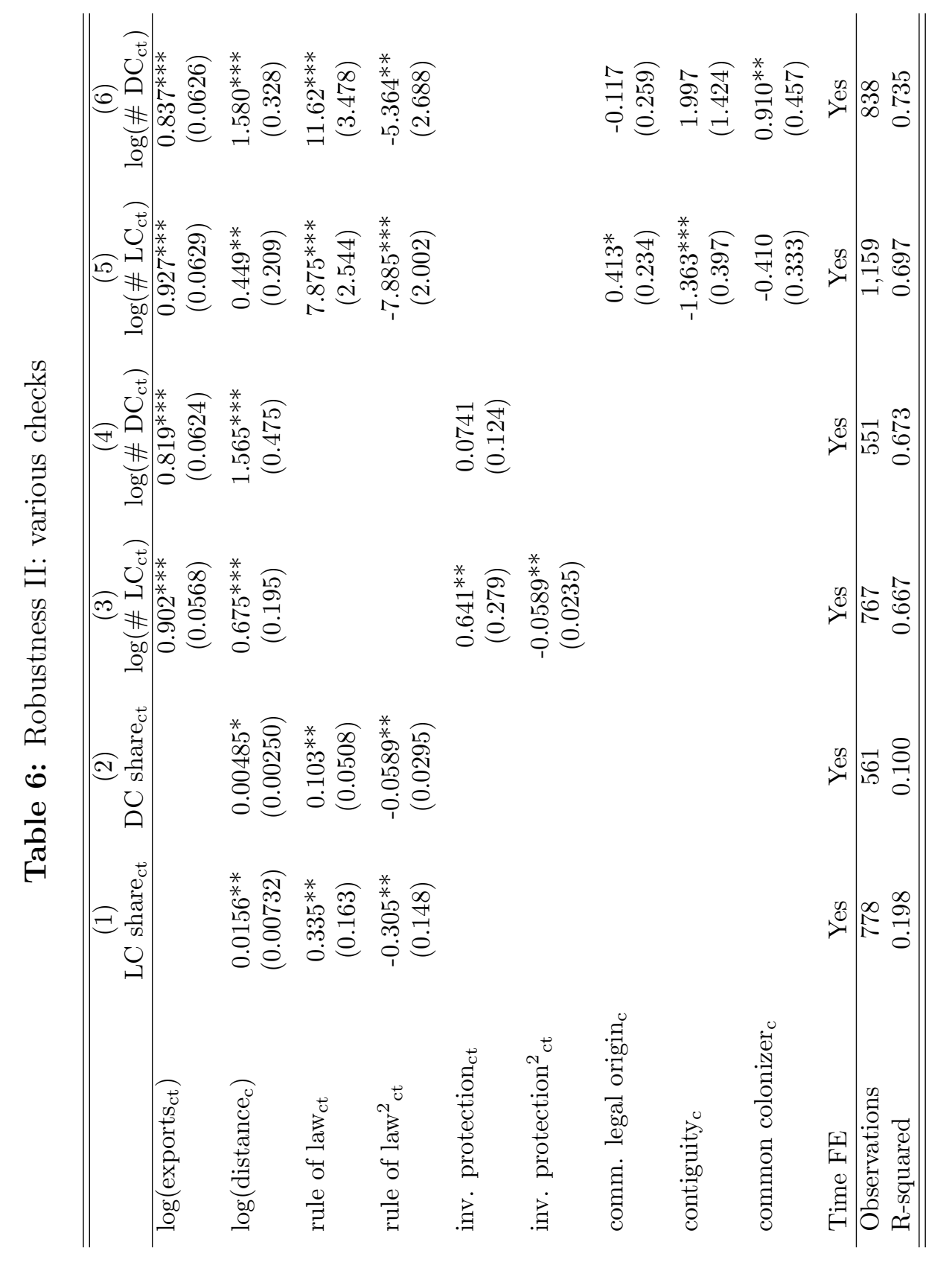

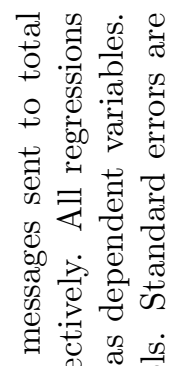

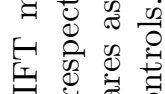

की

⿻上丨

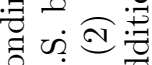

क्ष

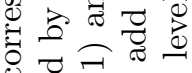

ช.

.

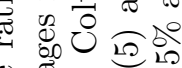

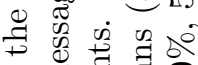

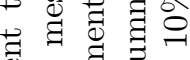

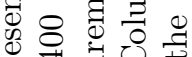

苍岛㤩.

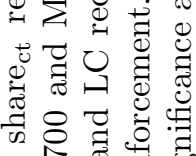

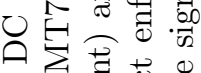

Ð

प원 융

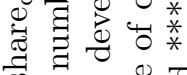

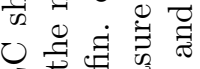

.

它

o

ఫै

ษิ สิ

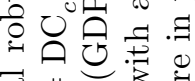

ส \#

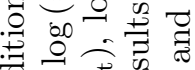

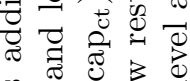

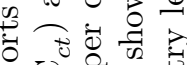

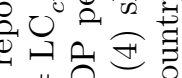

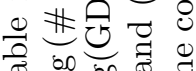

ॠ $80.0 \%$

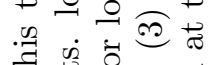

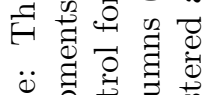

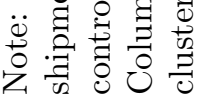


Table 7: Robustness III: trade finance claims as dependent variable

\begin{tabular}{|c|c|c|c|c|c|}
\hline & $\begin{array}{c}(1) \\
\log \left(t f_{c t}\right)\end{array}$ & $\begin{array}{c}(2) \\
\log \left(t f_{c t}\right)\end{array}$ & $\begin{array}{c}(3) \\
\text { tf share } \text { st }_{\text {ct }}\end{array}$ & $\begin{array}{c}(4) \\
\log \left(t f_{c t}\right)\end{array}$ & $\begin{array}{c}(5) \\
\log \left(t f_{c t}\right)\end{array}$ \\
\hline $\log \left(\operatorname{exports}_{\mathrm{ct}}\right)$ & $\begin{array}{l}1.038^{* * *} \\
(0.0535)\end{array}$ & $\begin{array}{c}1.020^{* * *} \\
(0.0545)\end{array}$ & & $\begin{array}{c}1.097^{* * *} \\
(0.0636)\end{array}$ & $\begin{array}{c}1.064^{* * *} \\
(0.0577)\end{array}$ \\
\hline $\log \left(\right.$ distance $\left._{c}\right)$ & $\begin{array}{c}0.397^{* *} \\
(0.188)\end{array}$ & $\begin{array}{c}0.333 \\
(0.298)\end{array}$ & $\begin{array}{c}0.118^{* * *} \\
(0.0422)\end{array}$ & $\begin{array}{c}0.838^{* * *} \\
(0.231)\end{array}$ & $\begin{array}{c}0.299 \\
(0.195)\end{array}$ \\
\hline rule of law $\mathrm{w}_{\mathrm{ct}}$ & $\begin{array}{c}7.116^{* * *} \\
(2.321)\end{array}$ & $\begin{array}{c}2.231 \\
(2.543)\end{array}$ & $\begin{array}{l}1.235^{* *} \\
(0.605)\end{array}$ & & $\begin{array}{c}7.765^{* * * *} \\
(2.372)\end{array}$ \\
\hline rule of law ${ }^{2}$ t & $\begin{array}{c}-7.786^{* * * *} \\
(2.105)\end{array}$ & $\begin{array}{l}-3.583 \\
(2.176)\end{array}$ & $\begin{array}{c}-1.136^{* *} \\
(0.491)\end{array}$ & & $\begin{array}{c}-8.195^{* * *} \\
(2.086)\end{array}$ \\
\hline long dist. dummy ${ }_{c}$ & & $\begin{array}{c}-2.213^{* *} \\
(1.117)\end{array}$ & & & \\
\hline 1.d. dummy $_{\mathrm{c}} *$ rule of law $\mathrm{w}_{\mathrm{ct}}$ & & $\begin{array}{c}10.31^{* *} \\
(3.995)\end{array}$ & & & \\
\hline 1.d. dummy $_{c} *$ rule of $\operatorname{law}^{2}$ ct & & $\begin{array}{c}-9.383^{* * *} \\
(3.402)\end{array}$ & & & \\
\hline inv. protection $_{\mathrm{ct}}$ & & & & $\begin{array}{c}0.761^{* *} \\
(0.322)\end{array}$ & \\
\hline inv. protection ${ }^{2} \mathrm{ct}$ & & & & $\begin{array}{c}-0.0752^{* *} \\
(0.0290)\end{array}$ & \\
\hline comm. legal origin $_{C}$ & & & & & $\begin{array}{l}-0.128 \\
(0.206)\end{array}$ \\
\hline contiguity $_{\mathrm{c}}$ & & & & & $\begin{array}{c}-1.157^{* * *} \\
(0.386)\end{array}$ \\
\hline common colonizer $_{\mathrm{C}}$ & & & & & $\begin{array}{l}0.0512 \\
(0.347)\end{array}$ \\
\hline Time FE & Yes & Yes & Yes & Yes & Yes \\
\hline Observations & 1,257 & 1,257 & 1,257 & 636 & 1,256 \\
\hline R-squared & 0.698 & 0.707 & 0.120 & 0.688 & 0.702 \\
\hline
\end{tabular}

Note: In this table, we employ U.S. banks' trade finance claims from the FFIEC 009 data as an alternative measure of firms' use of LCs. $\log \left(\mathrm{tf}_{\mathrm{ct}}\right)$ stand for the total end-of-quarter claims of all reporting banks on country $c$. tf share ct $_{\text {is }}$ the ratio of total end-of-quarter claims over quarterly U.S. exports to destination country c. Columns (1) and (2) replicate the baseline results. Column (3) employs the ratio of claims over exports as the dependent variable. Column (4) uses investor protection as an alternative measure of contract enforcement. Column (5) includes additional control variables. All regressions include log(GDP per cap $\left._{\mathrm{ct}}\right), \log \left(\mathrm{GDP} \text { per cap } \mathrm{pt}_{\mathrm{ct}}\right)^{2}, \log$ (fin. development) and the dummy variable that captures LC requirements. Standard errors are clustered at the country level and are in parentheses. ${ }^{*},{ }^{* *}$ and ${ }^{* * *}$ denote significance at the $10 \%, 5 \%$ and $1 \%$ level.

Table 8: Different forms of trade finance and corresponding trade transactions that could be captured in the FFIEC009 claims data

\begin{tabular}{lccc} 
& U.S. exports & U.S. imports & Third party trade \\
\hline Pre-export financing & - & $\mathrm{X}$ & $\mathrm{X}$ \\
Pre-import financing (affiliate) & $\mathrm{X}$ & - & $\mathrm{X}$ \\
LC issuance (affiliate) & $\mathrm{X}$ & - & $\mathrm{X}$ \\
LC confirmation & $\mathrm{X}$ & - & $\mathrm{X}$ \\
forfeiting/ factoring & $\mathrm{X}$ & - & $\mathrm{X}$ \\
\hline
\end{tabular}

Note: - indicates that this combination of instrument and underlying transaction cannot be captured in the data by definition. $\mathrm{X}$ means that it could be included in the data. 


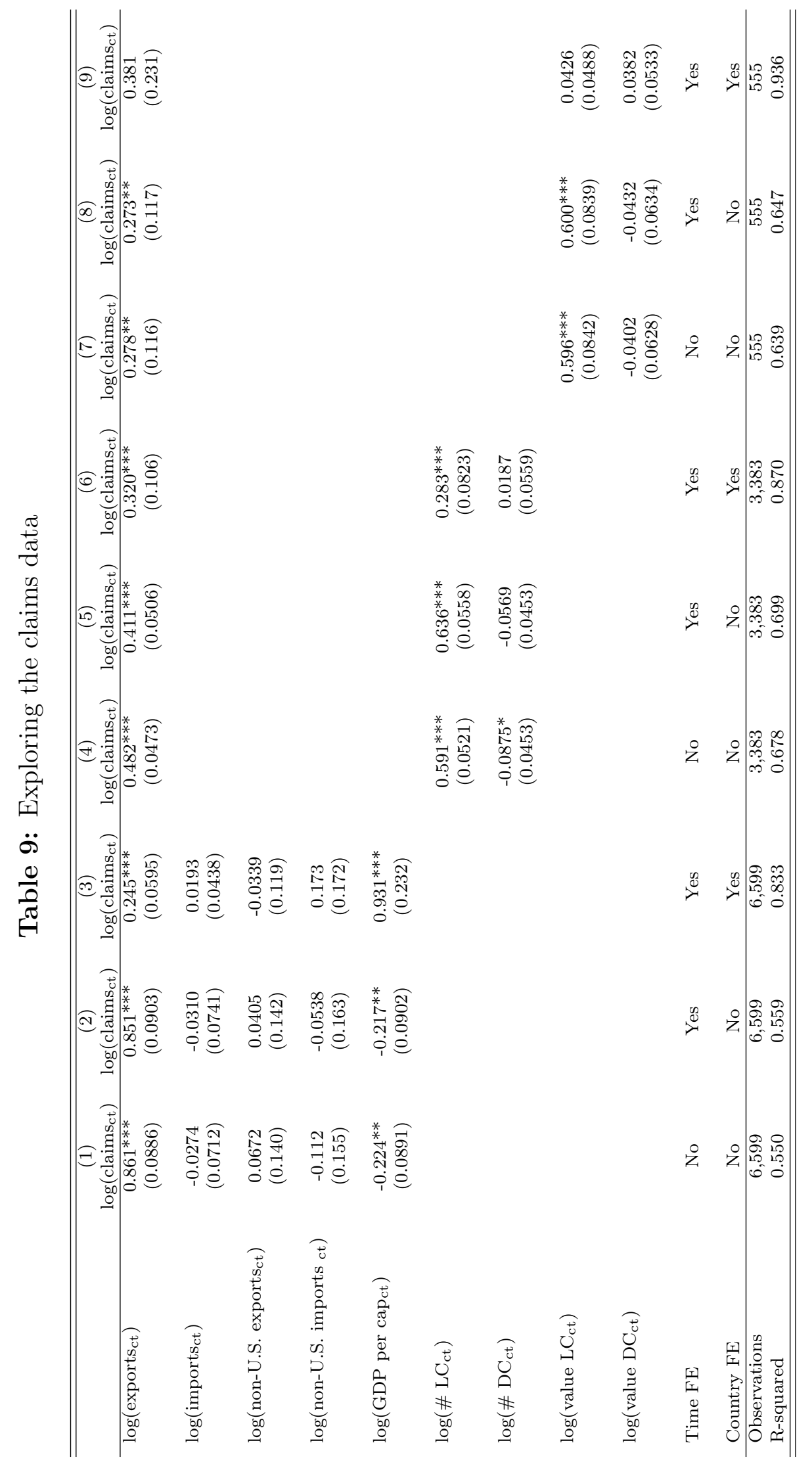

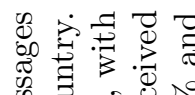

W

a 0.5

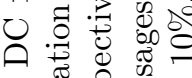

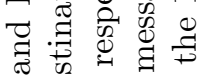
0 0 믈 월 政

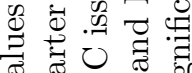
잉 긍요 果云 夏

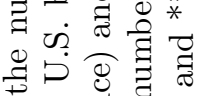
ซ สี 象记 난 $\frac{\pi}{4}$ o of 8

\& O I 80 .

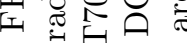

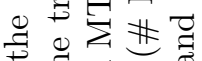
$\mp=50$ 명 $\forall=\square$

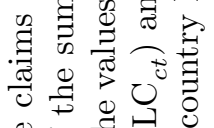

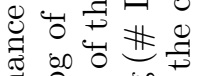
目응

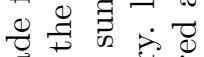
里包 욜 ठ엉

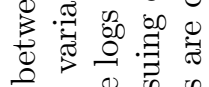

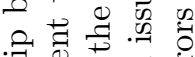
㭔 \% 串 品焉

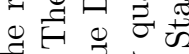
讨 政远 궁 of ส $\Xi$ च $\because 世$ 宩 สิ 工 $^{\circ}$

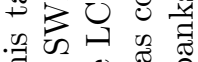

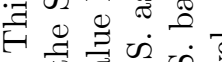
讨造包 운 


\section{F Figures}

Figure 1: How a letter of credit works

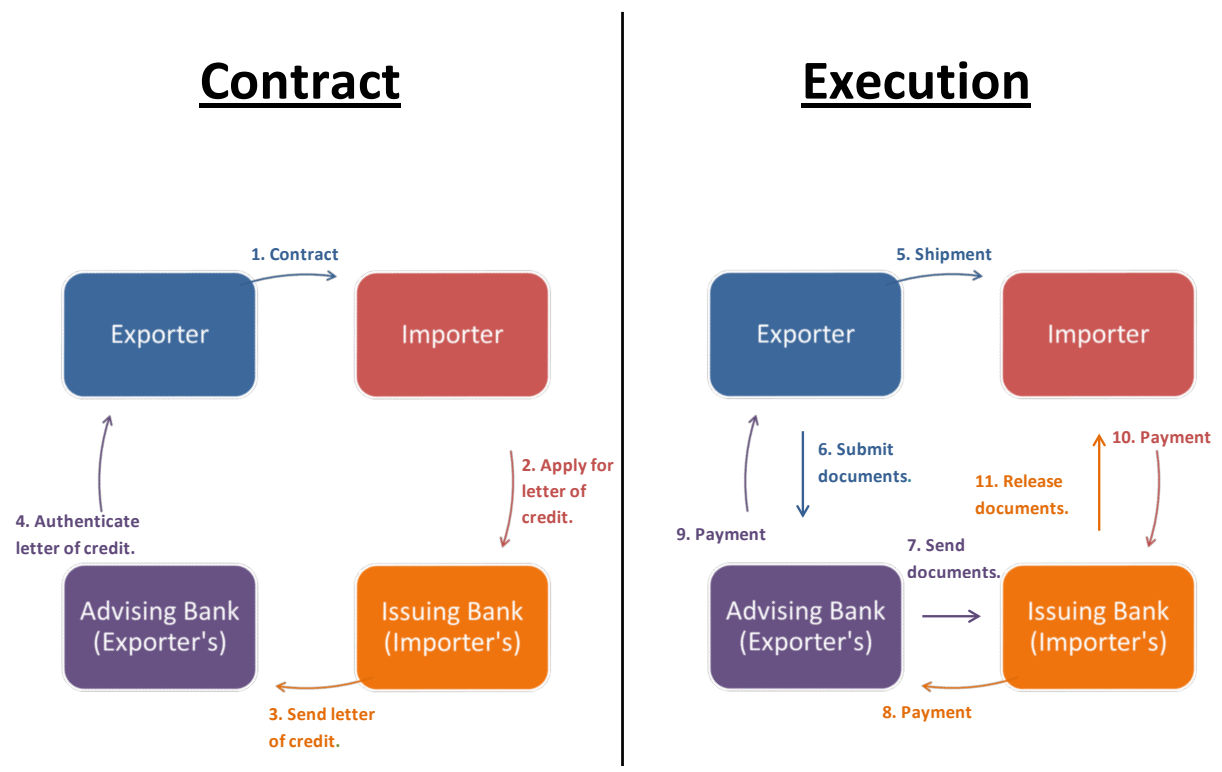

Figure 2: How a documentary collection works

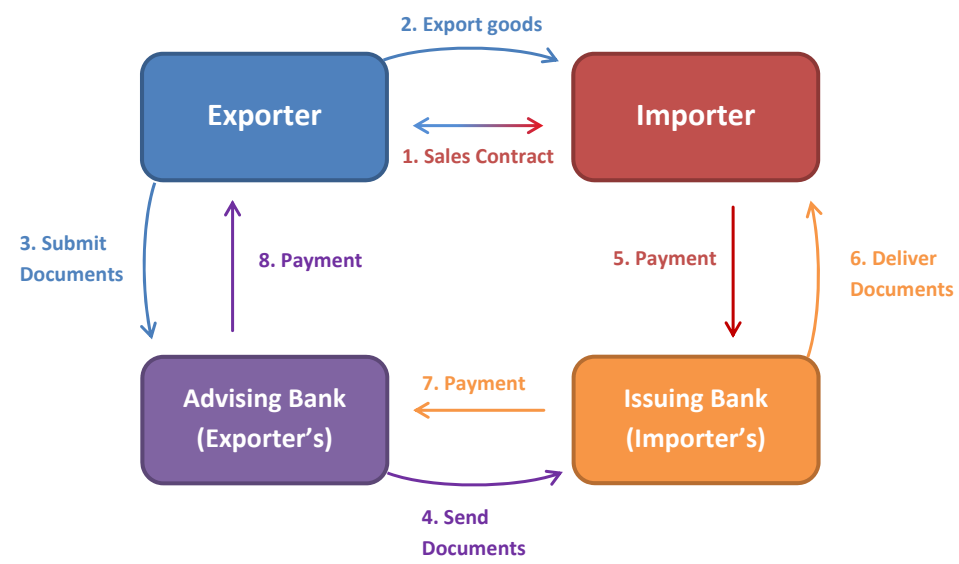


Figure 3: Geographical distribution of SWIFT messages

SWIFT Values as Percentage of Exports by Top 20 US Export Destinations

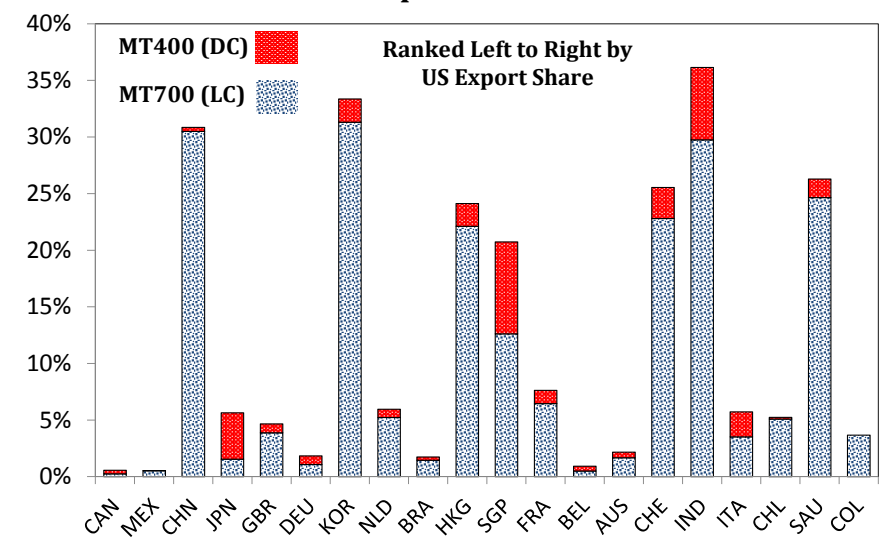

\section{LC and DC Intensities for Top 10 Countries}

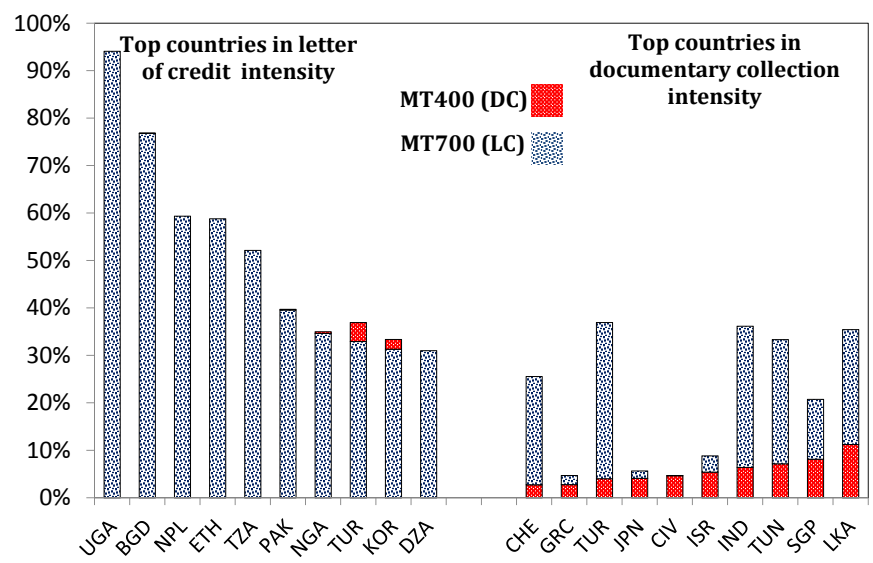

Note: The top chart shows the top 20 U.S. export destinations ranked from the left to the right together with each destination's ratio of LC and DC message values to U.S. exports over the period from 2010 q4 to 2012 q2. The bottom chart shows the countries with highest LC intensity (on the left) and DC intensity (on the right) defined as the value of messages divided by total U.S. exports to that country. Data sources: FFIEC 009 Reports, SWIFT Institute, IMF Directions of Trade Statistics. 
Figure 4: Relationship between a country's insurance premium and country risk

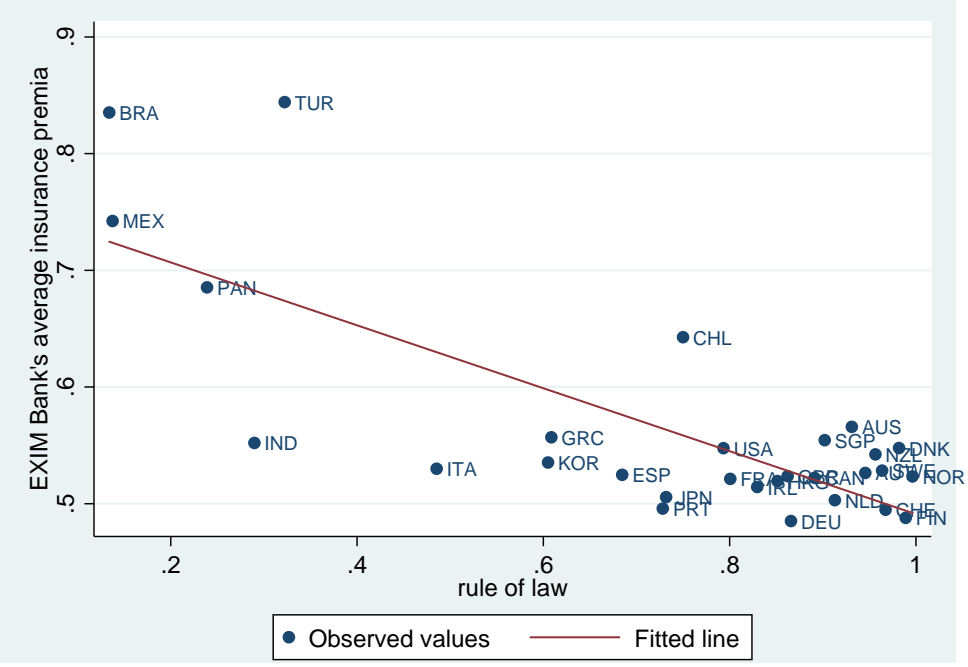

Note: The graph shows the average insurance premium charged by the U.S. Export-Import Bank for export transactions in the year 2004 plotted against a measure of the rule of law in the importing country from the World Bank's World Government Indicators. Sources: ExIm Bank, World Government Indicators.

Figure 5: Profits as a function of contract enforcement in the destination country

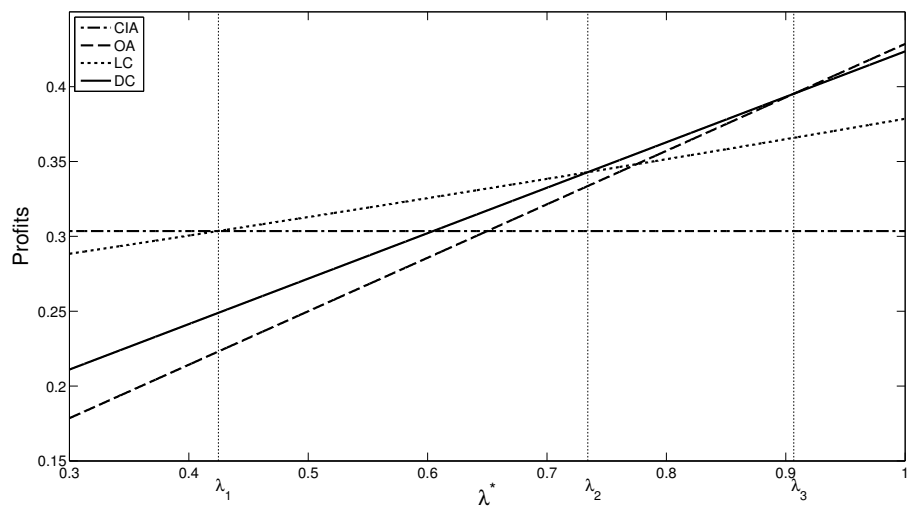

Note: The graph plots the expected exporter profits under the four payment forms (cash-inadvance, open account, documentary collection and letter of credit) as a function of contract enforcement $\lambda^{*}$ in the destination country. Parameters are: $\eta=\eta^{*}=0.75, \lambda=0.8, R=1.5$, $K=1, r^{*}=r=0.05, f^{D C}=0.5 \%, m=5 \%, \lambda^{*} \in[0.3,1], \phi^{D C}=0.05$ and $\phi^{L C}=0.2$. 
Figure 6: Relative profitabilities of letters of credit and documentary collections

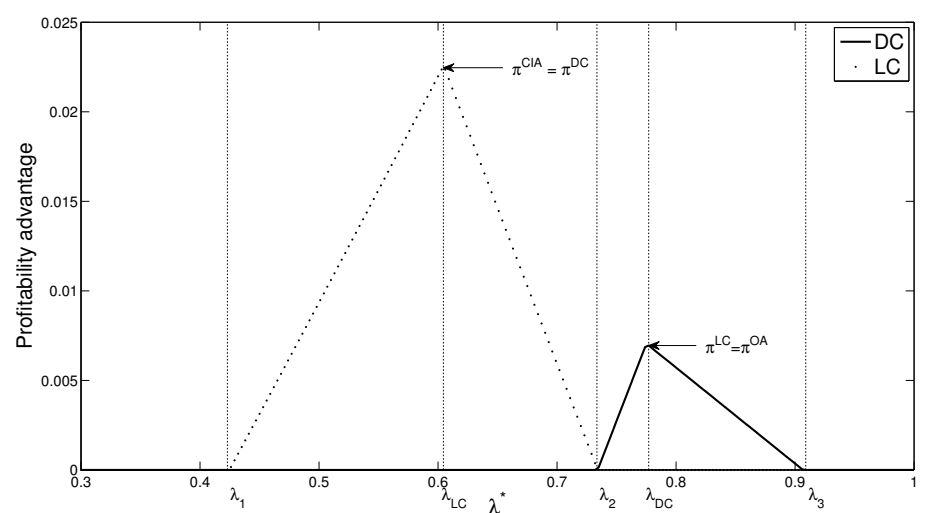

Note: The graph displays the relative profitabilities of a letter of credit and a documentary collection as functions of contract enforcement $\lambda^{*}$ in the destination country. It depicts the difference between profits when a letter of credit (documentary collection) is used and the profits with the most preferred alternative payment method. At $\lambda *_{L C}$, the exporter is indifferent between a documentary collection and cash-in-advance terms. At $\lambda *_{D C}$, the exporter is indifferent between a letter of credit and an open account. Parameters are: $\eta=\eta^{*}=0.75, \lambda=0.8, R=1.5, K=1$, $r^{*}=r=0.05, f^{D C}=0.5 \%, m=5 \%, \lambda^{*} \in[0.3,1], \phi^{D C}=0.05$ and $\phi^{L C}=0.2$.

Figure 7: Simulated shares of the four payment forms

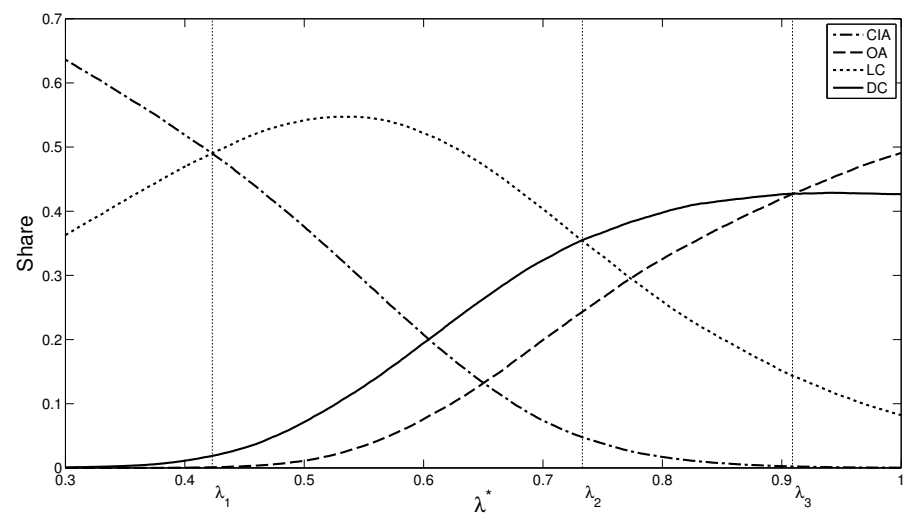

Note: The graph shows the shares of the four payment contracts in total transactions for different levels of contract enforcement $\lambda^{*}$ in the destination country in a simulated example. Parameters are: $\eta=\eta^{*}=0.75, \lambda=0.8, R=1.5, K=1, r^{*}=r=0.05, f^{D C}=0.5 \%, m=5 \%, \lambda^{*} \in[0.3,1]$, $\phi^{D C}=0.05$ and $\phi^{L C}=0.2$. The shocks to the profitability of the four contracts are assumed to be independently normally distributed with variance 0.1 and mean 1 . 
Figure 8: Estimated relationship between the use of LCs and DCs and the rule of law

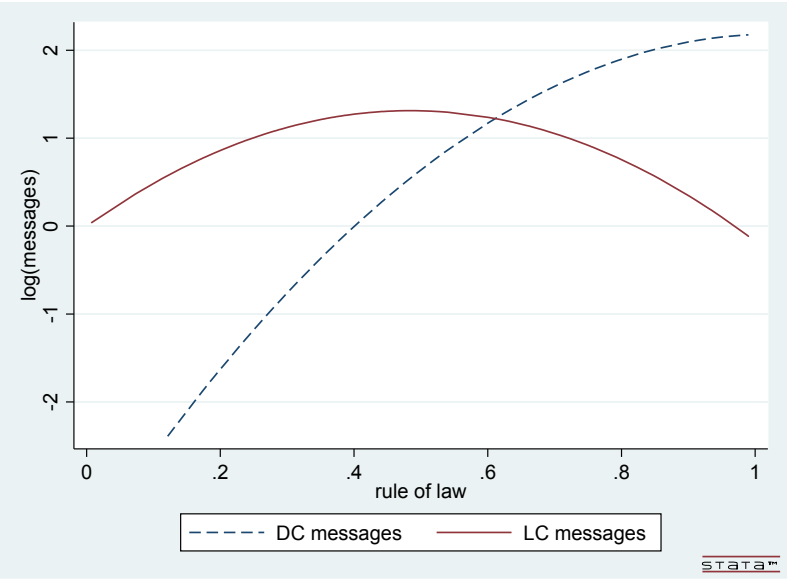

Note: The figure illustrates how the use of letters of credit and documentary collections varies with the rule of law in the destination country based on the estimated coefficients in column (3) of table 2. The solid line shows the log number of LC messages. The dashed line depicts the log number of DC messages. 
Figure 9: Interaction between a country's rule of law and distance from the U.S.
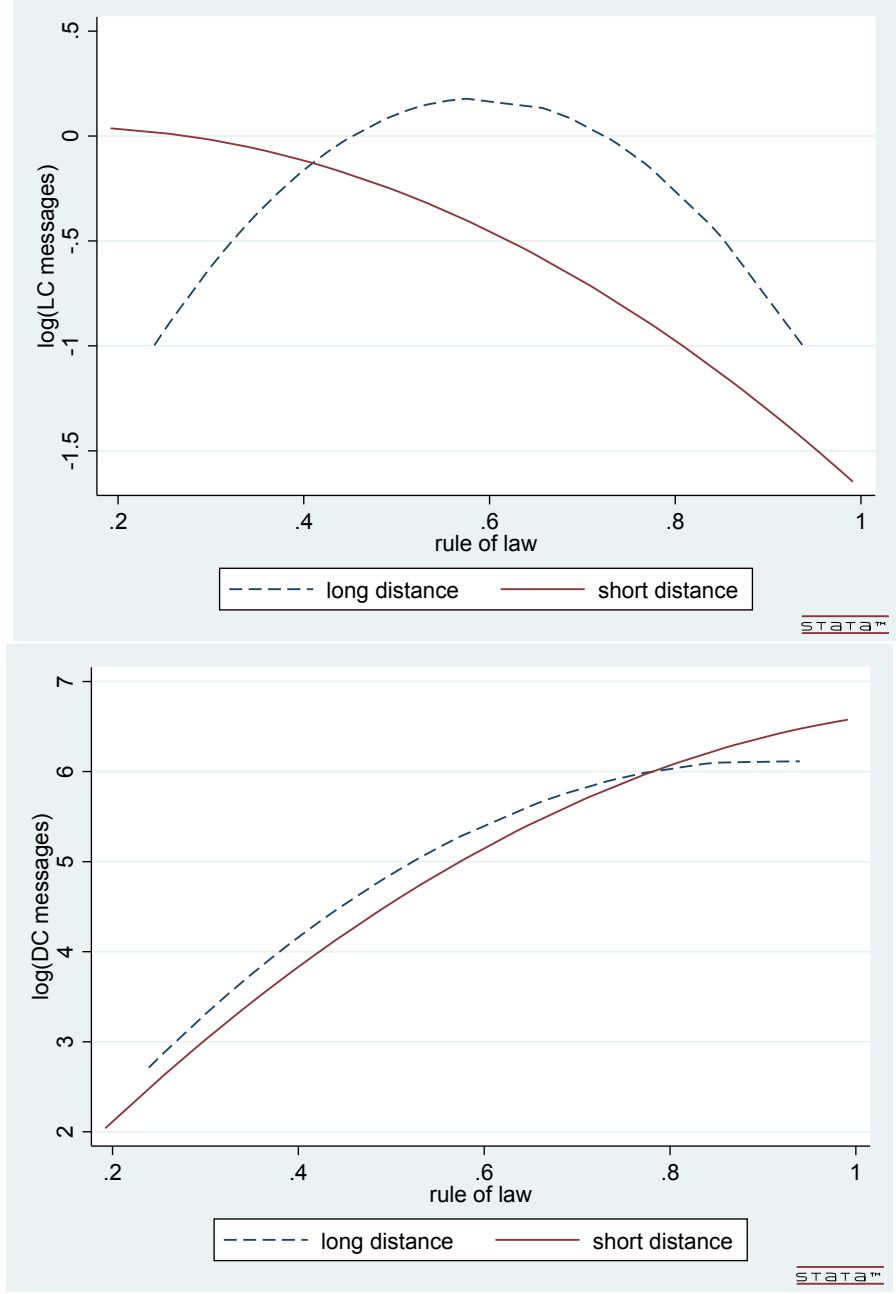

Note: The charts in this figure illustrate how the relationship between LC use (DC use) and the rule of law in the destination country varies with distance to the U.S. They are based on the estimated coefficients in columns (5) and (6) of table 2, respectively. The solid line in each of the two charts shows the relationship between the use of LCs and DCs, respectively, and the rule of law in the importing country for countries with a $\log$ distance form the U.S. below the median. The dashed line depicts the same relationship but for countries with a log distance above the median. 
Figure 10: Average transaction size in the data

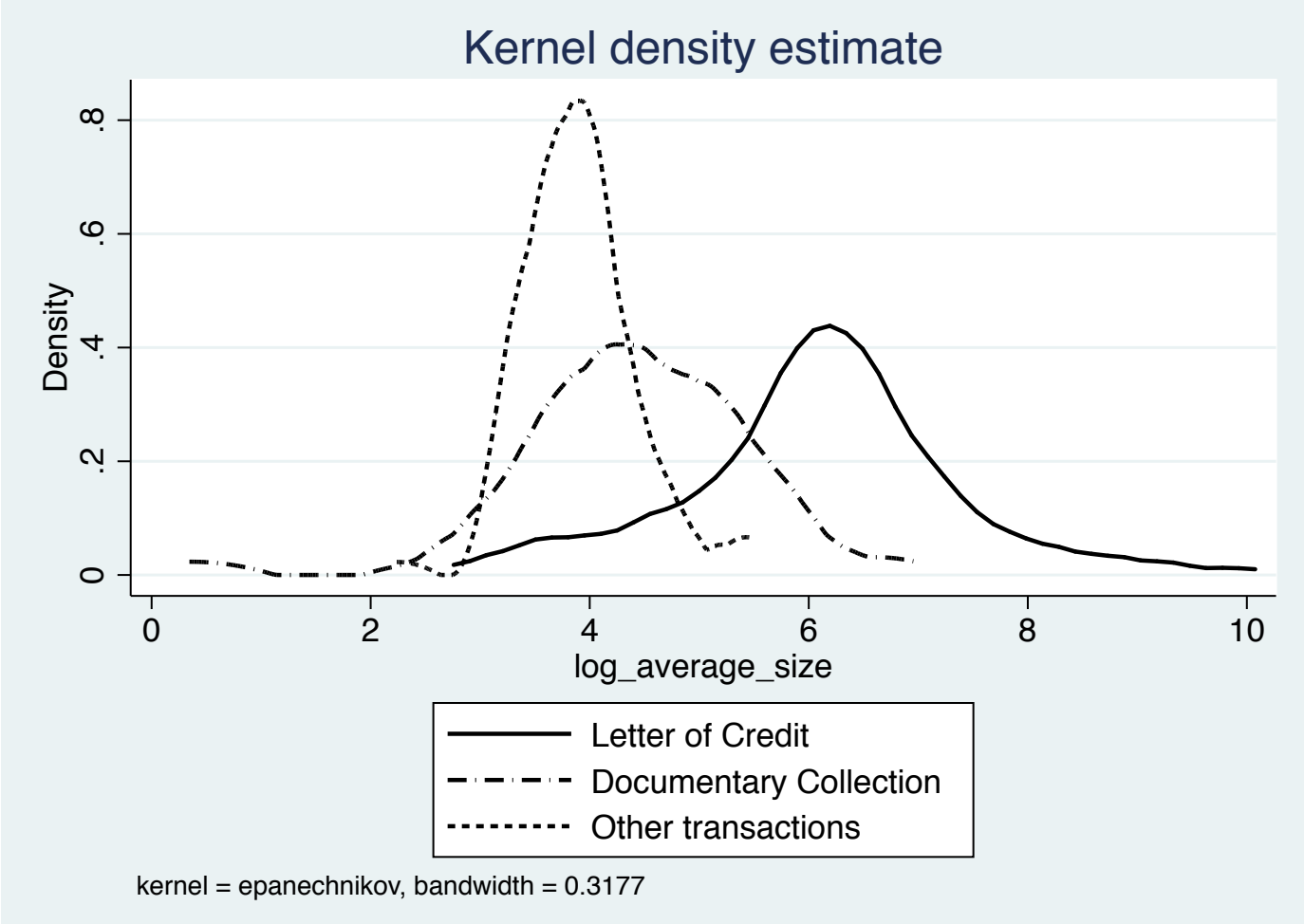

Note: This figure depicts the kernel density estimates of the average transaction size by country for the period from 2010 q4 to 2012 q4. Densities are estimated for those 84 countries for which data is available on both the numbers and the total values of letters of credit, documentary collections and export transactions. 
Figure 11: Semi-parametric estimation
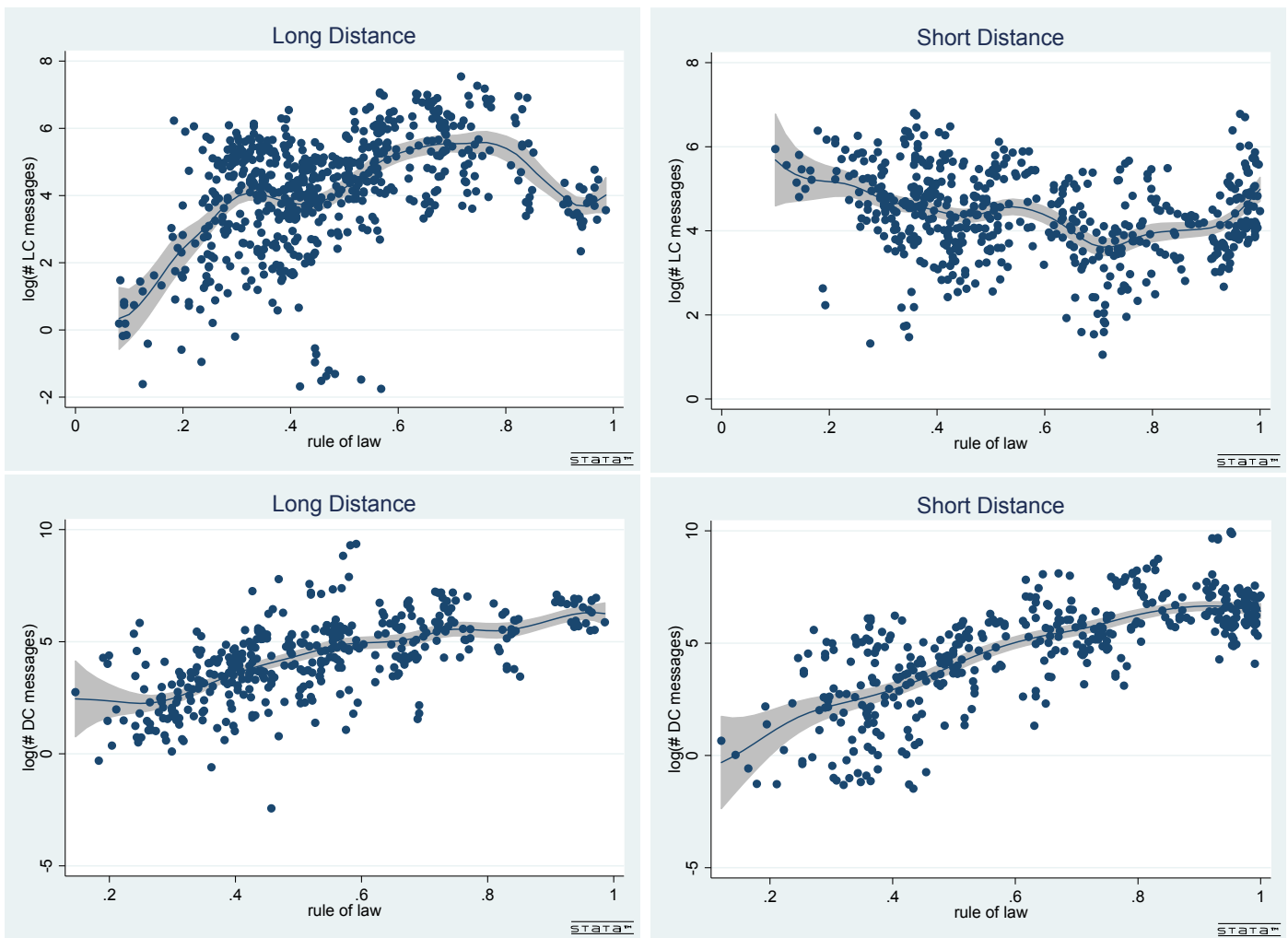

Note: Each chart in the figure shows the relationship between either the number of LC messages or the number of DC messages and the rule of law in the importing country and is obtained from semi-parametric estimation. Charts on the left (right) display the relationship for importing countries with an above (below) median log distance from the United States. In the charts at the top, the number of LC messages is regressed on log exports, log distance, log GDP per capita, log GDP per capital squared, financial development and a dummy for LC requirements, which enter the regressions as linear terms. Rule of law enters non-linearly. The charts at the bottom use the number of DC messages as the dependent variable. 